\title{
Superlubricitive engineering-Future industry nearly getting rid of wear and frictional energy consumption
}

\author{
Jianbin LUO*, Xiang ZHOU \\ State Key Laboratory of Tribology, Tsinghua University, Beijing 100084, China \\ Received: 31 December 2019/Revised: 29 March 2020 / Accepted: 02 April 2020 \\ (C) The author(s) 2020.
}

\begin{abstract}
Superlubricity has been developing very rapidly in recent years as a new and important area in tribology. Many new phenomena and materials, as well as some new mechanisms in both liquid and solid superlubricity have been obtained. In liquid superlubricity, tens of new kinds of liquids with superlubricity have been found (e.g., water-based liquids, oil-based lubricants, and liquids combined with additives of two-dimensional (2D) materials that exhibit very good superlubricity properties under high pressure). In the field of solid superlubricity, more materials with superlubricity have been observed, including graphene-to-graphene surfaces, highly oriented pyrolytic graphite to graphene surfaces, and heterostructure surfaces where a friction coefficient as low as 0.00004 has been obtained. However, superlubricity is still under laboratory research. What is the future of superlubricity? What is the barrier restricting superlubricity from industrial applications? How do we transfer superlubricity from scientific research to industrial application? These questions and application fields of superlubricity in near future have been analyzed, and the concept of "superlubricitive engineering" has been proposed in the present work.
\end{abstract}

Keywords: superlubricitive engineering; superlubricity; liquid superlubricity; solid superlubricity; two-dimensional (2D) material; lubrication

\section{Introduction}

As the world's economy develops rapidly, losses caused by friction and wear in various fields increase accordingly, aggravating the energy crisis. According to statistical information, $\sim 30 \%$ of the world's primary energy resources is consumed by friction and $\sim 80 \%$ of the mechanical components fail because of wear $[1,2]$. Based on different developing modes, frictional losses account for $\sim 2 \%-7 \%$ of GDP per year, translating to 1.7-6.0 trillion US dollars (USD) worldwide in 2018. For countries with advanced manufacturing industries, such as China, the USA, Germany, and Japan, the percentage of frictional losses can be even higher. For example, Holmberg and Erdemir [3] reported that $\sim 3$ trillion USD is spent on the fuel used to overcome friction by passenger cars in the world per year. If friction can be reduced by $18 \%$, 90 billion USD can be saved, and $\mathrm{CO}_{2}$ emissions can be reduced by 290 million tons a year, with an accompanying vast decrease in PM2.5 emissions. Therefore, developing new anti-wear and lubrication technologies has become an important target for scientific researches in order to save energy resources, to relieve environmental pollution and to improve the ecological environment. On the other hand, the existence of friction is necessary in some cases, such as transmission agents, e.g., friction wheels and belts or, more commonly, brakes in all kinds of vehicles. Under such circumstances, friction is important for proper operation of the corresponding structures, but wear may still be a problem because it restricts the lifetime of these components.

* Corresponding author: Jianbin LUO, E-mail: luojb@mail.tsinghua.edu.cn 
Consequently, a balance between temperate friction and low wear must be acquired, meaning that precise control of friction may be helpful.

In recent years, the discovery of superlubricity, which provides a new and important method to solve the energy consumption problem, has received intense attention in the fields of tribology, mechanics, and physics. Theoretically, superlubricity is the lubricating state in which friction almost disappears or even vanishes completely [4]. Practically, superlubricity is said to be achieved when the coefficient of friction (COF) is at $10^{-3}$ level or less, which is the magnitude of measurement signal error ten years ago [5]. Under a superlubricity state, the COF will decrease by orders of magnitude compared with that of normal lubricating oils, and the wear rate is also quite low. As a result, realization and application of superlubricity can not only slash energy consumption but also greatly reduce the wear and failure of various kinetic pairs, which can significantly improve the lifetime of different devices and the performance of the kinetic pairs.

Superlubricity will greatly progress human civilization, and its influence will be profound. Superlubricity research involves tribology, nanometrology, materials science, quantum mechanics, atomic and molecular physics, and many other fields. It has been found that under certain working conditions, some materials can exhibit superlubricity behavior in the friction process. The specific mechanism behind this phenomenon is still not well understood, and some of the experimental results cannot be explained with current theory. Research concerning major scientific issues usually undergoes three steps: 1) discovery of new phenomena; 2) revelation of mechanisms; and 3) application of theoretical achievements. Superlubricity research is now going through the first and second steps. In the past decade, significant breakthroughs have been made in discerning the superlubricity mechanism and in developing superlubricity materials. The next few decades will be a critical period for the industrial realization and application of superlubricity.

Here, we present the concept of "Superlubritive Engineering" as the first step to turn superlubricity from laboratory investigation into engineering research. We must combine the concepts, mechanisms, and materials of superlubricity with real engineering working conditions and develop new superlubricity techniques to address practical engineering problems. The implications of superlubricitive engineering can be abundant. In numerous areas, such as the fields of transportation, fluid machinery, manufacturing, space technologies, and renewable energy, superlubricitive technology can be widely used in the near future. Superlubricitive technology in gearboxes, bearings, slideways, pumps, hydraulic components, and sealing parts can all be gradually developed. Even in the field of electronics, superlubricitive technologies have some possibilities to be used in switches, relays, or even micro-generators so that the lifetime of these components or devices can be greatly increased. In the field of underwater navigation, superlubricity can help reduce energy cost and enhance moving speed. In outer space exploration, spacecraft energy consumption can be vastly reduced by superlubricity and its lifetime will increase.

\section{Recent advances in superlubricity research}

Superlubricity can usually be classified into solid and liquid superlubricity, according to whether or not liquid exists in the tribo-pair. However, this classification is more for convenience than a precise definition. Even though the underlying mechanism of the two types are totally different, they may sometimes be used together and are interlinked. In many cases, solid contact also exists in a so-called liquid superlubricity state. We might as well give such situation an individual classification, namely, solid-liquid combined superlubricity.

\subsection{Solid superlubricity}

In the early 1990s, the solid superlubricity regime was proved by Shinjo and Hirano [4] in a solid-state system through a theoretical calculation, and investigations concerning superlubricity in solid contact have been ongoing ever since. In the context of the mechanism of solid superlubricity, structural factors [6-8] such as incommensurability and lattice mismatch, as shown in Fig. 1(a), have attracted intensive attention. We are also pleased to see that other factors such as interfacial electrical properties and tribo-induced chemical reactions are attracting increased interest (e.g., superlubricity with diamond-like carbon films [9]). 


\subsubsection{Two-dimensional (2D) materials and superlubricity}

2D materials are a group of fast emerging materials with layered structure. Low interlayer interaction and regular atom arrangement endow these materials with the potential to achieve super-low friction [10, 11]. The first experimental proof for superlubricity in 2D materials can be traced back to 1993, when Martin et al. [12] obtained a COF as low as $10^{-3}$ in a $\mathrm{MoS}_{2}$ coating under ultrahigh vacuum, as shown in Fig. 1(b). They attributed the origin of superlubricity to the frictional anisotropy on sulfur-rich basal planes.

Such anisotropy was then discovered in graphite by Dienwiebel et al. [13]. They used a tungsten tip of a frictional force microscope to slide against the graphite surface, and found that there was a peak value of frictional force when the sliding direction was aligned with the graphite's lattice orientation; between the two frictional force peaks, the friction was quite low, as shown in Fig. 1(c). Their results strongly suggested the relationship between solid superlubricity and commensurability on the interface: Low friction between peaks occurs because the graphite flakes adhered to the tip and the underlying graphite substrate exhibited incommensurate stacking.

To some extent, this research strategy sets the tone for subsequent superlubricity studies concerned with 2D materials. Tip scanning technologies such as frictional force microscopy and atomic force microscopy (AFM) remain the most important experimental methods for detection of superlubricity, and many of the results obtained are explained by incommensurability. Researchers tend to seek fancier strategies to utilize the scanning tip or ways to obtain lower COF values under more severe conditions. In our group, Liu et al. [8] realized robust superlubricity with multi-point contacts between 2D materials. Li et al. [14] slid an AFM tip directly against graphite and obtained a COF as low as 0.0003 under a contact pressure of $2.52 \mathrm{GPa}$. Liu et al. [15] developed a thermally assisted mechanical exfoliation and transfer method to wrap different kinds of $2 \mathrm{D}$ materials onto the AFM tip, giving the tip the ability to directly detect interlayer coupling and realizing a low COF value of 0.0001 (Fig. 1(d)). Recently, they further realized an even lower COF of 0.00004 . These works are all related to the incommensurate contacts.

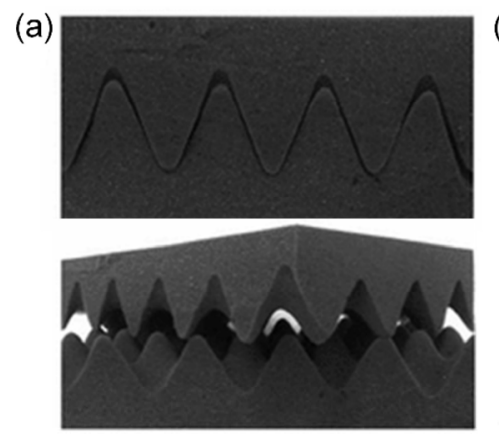

(c)

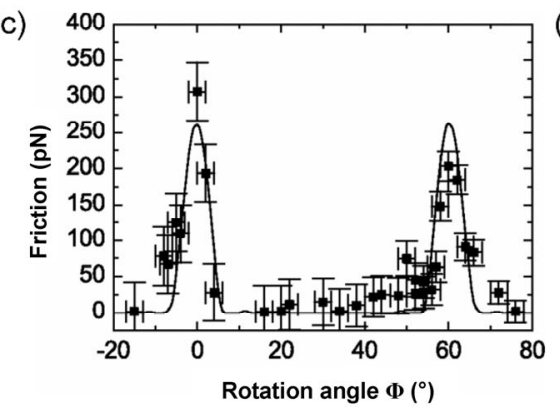

(b)

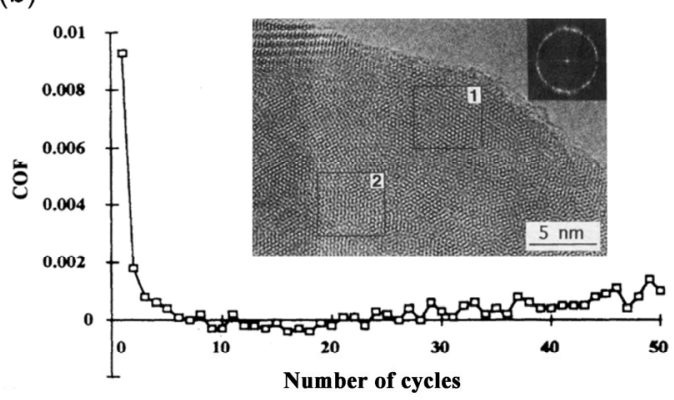

(d)

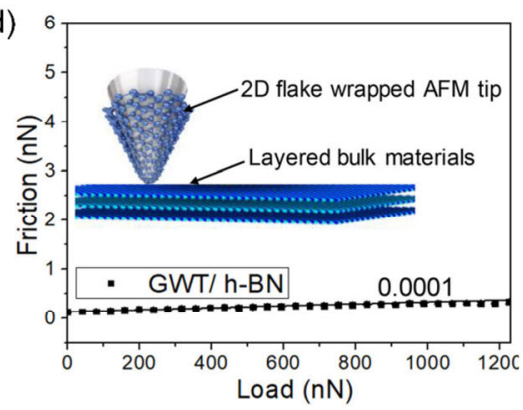

Fig. 1 (a) Illustrations of commensurate (upper) and incommensurate (lower) states. Reproduced with permission from Ref. [7]. (C) American Physical Society, 2012. (b) First case of 2D material superlubricity obtained in $\mathrm{MoS}_{2}$, with a COF in the range of 0.001 . Reproduced with permission from Ref. [12]. (C) American Physical Society, 1993. (c) Friction anisotropy measured in graphite; the period of change in friction is consistent with the lattice feature angle. Reproduced with permission from Ref. [13]. (C) American Physical Society, 2004. (d) Superlubricity between graphene-wrapped AFM tip and h-BN surface. Reproduced with permission from Ref. [15]. (C) American Chemical Society, 2018. 
Are there other factors that may contribute to superlubricity of 2D materials besides the mechanism of commensurate and incommensurate stacking? Berman et al. [16] outlined typical mechanisms for energy dissipation, among which phonons, deformation on the interface, and thermal and electronic effects are mentioned. Wang et al. [17] discovered through molecular dynamic (MD) simulation that when uniaxial or biaxial stress was applied to the substrate, robust superlubricity between two different graphene layers (which is independent of orientation) could be obtained. This is because the stretching of the graphene lattice can lead to complete lattice mismatch and the formation of a Moiré pattern. In another MD simulation, Liu et al. [18] claimed that vacancies in graphene may increase surface roughness and out-ofplane flexibility or even bond with the AFM tip and thus enhance friction. Wang et al. [19] used density functional theory (DFT) calculations to show the influence of interfacial charge density fluctuation to potential energy corrugation and superlubricity. Sun et al. [20, 21] found through DFT calculations that there would be an abnormal decrease of friction at the graphene/graphene interface under a certain critical normal load, because a high normal load forced the corrugated potential energy face to become smoother, which would suppress energy dissipation effectively.

Another problem concerning 2D material solid superlubricity is that most of the current results can only be obtained at the nanoscale, restricting its application in industry. Therefore, scaling up of the superlubricity interface is also an important issue. In our group, Liu et al. [8] designed a tribo-pair between graphene-coated $8 \mu \mathrm{m}$ microspheres and graphene or hexagonal boron nitride (h-BN) and achieved robust superlubricity with a COF of 0.0025 independent of the slip direction of graphene under a contact pressure of $1 \mathrm{GPa}$, as shown in Fig. 2(a). Song et al. [22] found anisotropy in the friction stress on graphite/h-BN heterojunction interface by using the AFM tip to push graphite flakes of several micrometers against the h-BN substrate. These microscale research efforts may form a vital step toward macroscale superlubricity, because they seek to go beyond the model of directly using the scanning tip and try to simulate real macroscale tribo-pairs.

There are also works focusing on the macroscale directly. Li et al. [23] discovered a COF of 0.001 (only occurring randomly) between a steel ball and a highly oriented pyrolytic graphite (HOPG) substrate. This was attributed to tribo-transferred multilayer nanoflakes (MGNFs) in the contact zone, as shown in Fig. 2(b). Berman et al. [24] obtained superlubricity when they let a hydrogenated diamond-like carbon (H-DLC) surface slide against nanodiamond-mixed molybdenum disulfide in a dry nitrogen atmosphere. Their result is explained by tribochemical reaction, in which diffusion of sulfur leads to amorphization in nanodiamonds, followed by formation of onion-like carbon structures (OLCs), as shown in Fig. 2(c). The existence of these OLCs results in smaller contact area and incommensurability. Gong et al. [25] used a combination method of pulse current plasma chemical vapor deposition and medium-frequency unbalanced
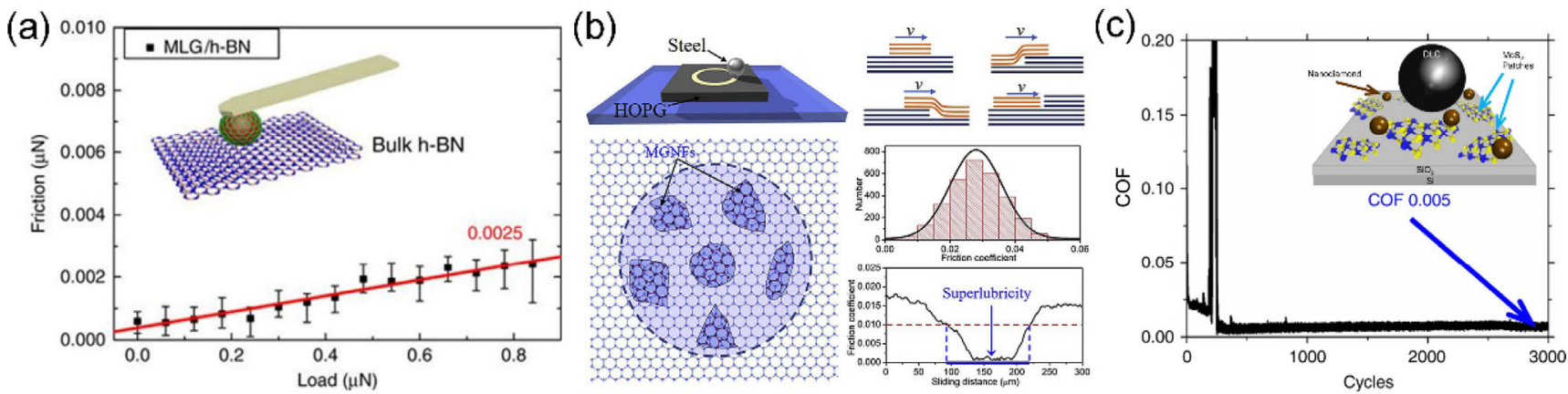

Fig. 2 (a) Microscale superlubricity obtained between a graphene-wrapped micro-ball and an h-BN surface [8]. (C) Springer Nature, 2017. (b) Macroscale superlubricity of a steel ball on HOPG, in which tribo-transferred MGNFs slide on the graphite surface with atomic steps and generate random occurrences of superlubricity. Reproduced with permission from Ref. [23]. C Elsevier Ltd., 2018. (c) OLC-induced macroscale solid superlubricity, the OLCs are the product of tribochemical reactions [24]. C Springer Nature, 2018. 
magnetron sputtering for macroscale synthesis of graphitic-like/ $\mathrm{MoS}_{2}$ films and achieved superlubricity with the $\mathrm{COF}$ as low as 0.004 under high contact pressure. It seems that, to understand the mechanism of macroscale superlubricity, we still have to investigate down to the micro- or even nanoscale. For example, even though the above works realized superlubricity at the macroscale, the explanation given by the authors is still microscale local incommensurability. The difference lies only in how incommensurability is achieved-By nanoflake transfer, tribochemical reaction, or by simply constructing an incommensurate interface directly.

\subsubsection{DLC films}

Compared to 2D materials, DLC films seem to be more compatible with macroscale applications, and they have already found their place in industrial applications [26-28]. Superlubricity was first obtained in this system by Erdemir [9, 29] in 2001. In that investigation, super-low COF and wear coefficients of $0.001-0.005$ and $10^{-11}-10^{-10} \mathrm{~mm}^{3} /(\mathrm{N} \cdot \mathrm{m})$, respectively, were realized. They also found that a higher hydrogento-carbon ratio in the source gas during the fabrication of DLC films would remarkably increase their anti-wear and anti-friction performance, because hydrogen could passivate the surface of DLC films and thus prevent chemical or physical processes from occurring. This work also revealed that tribochemistry is the main mechanism behind DLC film superlubricity and that the presence of hydrogen is necessary for guaranteeing the lubrication quality of DLC films.

Superlubricity of DLC films can be maintained under quite severe conditions. A COF of 0.008 was observed under temperatures as high as $600{ }^{\circ} \mathrm{C}$. Such high temperature facilitates oxidation reactions and benefits the formation of self-generated lubricious composite oxides consisting of $\gamma-\mathrm{Fe}_{3} \mathrm{O}_{4}$ and $\mathrm{SiO}_{2}$ during the running-in process, which will provide repulsive electrostatic forces in the contact area. The shielding action of hydrogen in DLC films also plays a vital role in this process [30]. Chen et al. [31] proposed a combination of focused ion beam slicing with scanning transmission electron microscopy and electron energyloss spectroscopy to detect the carbonaceous sliding interface. Their results demonstrated that this state-ofthe-art technique could provide ultra-high imaging resolution and confirmed the dominating influence of tribo-induced interfacial nanostructures in governing the superlubricity for hydrogen-rich DLC films in dry sliding contact. Recently, they obtained a COF of $<0.0001$ for a DLC film at $-170{ }^{\circ} \mathrm{C}$ under a pressure of 1.4 GPa. Mutyala et al. [32] demonstrated that using graphene/MoS ${ }_{2}$ as a solid lubricant on steel-H-DLC interface can reduce friction and wear even under high contact pressure and sliding speed by the generation of amorphous carbon mixed graphene layers. However, according to the investigation by Liu et al. [33] concerning the influence of sliding speed, superlubricity can only be maintained under low sliding speed. The failure of superlubricity under high sliding speed is attributed to neither friction heat nor the breaking of hydrogen passivation but to the absence of a transfer layer, the graphization of which is believed to be important for ultra-low friction.

Superlubricity of DLC films is very sensitive to the environmental atmosphere. Liu et al. [34] found that the processes of an $\mathrm{Al}_{2} \mathrm{O}_{3}$ ball sliding against an H-DLC-film-coated silicon substrate under humid air and vacuum are different, as shown in Fig. 3. In humid air, superlubricity cannot appear and friction is lower when the normal load becomes higher. In contrast, in vacuum, superlubricity can be observed only under low normal load; when the normal load gets

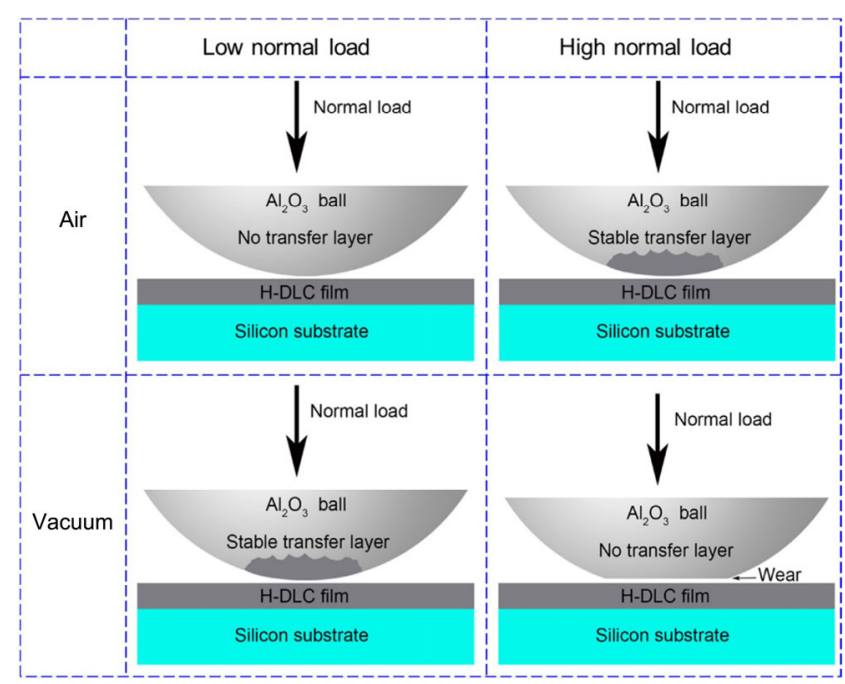

Fig. 3 Lubricating performance of an H-DLC film in air and vacuum. In air, the transfer layer can only come into being under a high normal load, in which case friction can be reduced. However in vacuum, the transfer layer can only be maintained under low normal load that generates superlubricity, which degrades under a high normal load [34]. C authors, 2019. 
high, the transfer layer on the $\mathrm{Al}_{2} \mathrm{O}_{3}$ ball cannot last for long and thus causes the failure of superlubricity. Braceras et al. [35] measured the COF values and electrical contact resistance (ECR) under different levels of humidity and discovered that the degradation of DLC coatings can continuously affect their ECR, indicating that ECR may act as an effective tool for on-line monitoring of the coating's state and lifetime.

Fabrication of DLC or other analogous carbon-based films is the precondition for all applications, and the strategy and the process of fabrication can profoundly influence film performance. Besides the hydrogen/ carbon ratio of the source gas in the DLC situation (mentioned above), Cui et al. [36] found that higher negative bias voltage used during magnetron sputtering when growing hydrogenated amorphous carbon (a-C:H) films could effectively extend the film's lifetime of superlubricity (0.002), although lower film thickness and bonded $\mathrm{H}$ contents were expected in such conditions. They pointed out that high bias voltage was helpful in improving the film compactness and the crosslinking degree of the polymer-like carbon network in the meantime.

\subsection{Liquid superlubricity}

Compared to investigations of solid superlubricity, most investigations concerning liquid superlubricity are conducted at the macroscale, which somehow gives it a natural advantage for application under various industrial conditions. In many cases, liquid superlubricity is obtained under thin film lubrication [37-41] or boundary lubrication, and the origin of liquid superlubricity can usually be attributed to a synergistic effect among different factors, the most frequently mentioned of which include absorption, tribochemical reaction, and formation of various layers [40, 42-50]. The mechanism of liquid superlubricity can be attributed to hydration force $[45,46]$, electric double layer force $[47,48]$, and hydrodynamic effects [42-44, 49, 50]. Here, we only emphasize some of the key points and quote some of the most recent works.

\subsubsection{Assistance of acid}

Research concerning the function of acid-based aqueous solutions in generating superlubricity is quite representative and the explanation for the underlying mechanism is quite complete and illuminating. It begins with the discovery by our group [43] that phosphoric acid can help realize superlubricity under ambient conditions, in which a COF of 0.004 between glass $/ \mathrm{Si}_{3} \mathrm{~N}_{4}$ and sapphire/sapphire surfaces has been obtained after a running-in process of $\sim 10 \mathrm{~min}$. Several factors contribute to this superlubricity. First, during the running-in process, rubbing-induced strong hydrogen bonds between $\mathrm{H}_{3} \mathrm{PO}_{4}$ and $\mathrm{H}_{2} \mathrm{O}$ molecules were left in the gap of the tribo-pair, which is capable of sustaining large pressure. The strong hydrogen bonds also benefit the formation of a layer of hydrated $\mathrm{H}_{2} \mathrm{O}$ molecules on the surface, which can vastly reduce shear resistance. Besides, interfacial Coulomb repulsion resulting from dipole-dipole interaction in $\mathrm{H}_{3} \mathrm{PO}_{4}$ is also contributory [43], as shown in Fig. 4(a). The running-in process can be divided into two steps. In the first step, an electrical double layer is formed first through protonation reactions, providing a repulsive interaction on the interface and a platform for the hydrogen-bond network. The COF decreases rapidly during this step. In the second step, free water between the solid surfaces evaporates gradually, leaving a layer consisting of hydrated water molecules, and the shear strength of water molecules is extremely low $[42,44,49]$. The mechanism of phosphoric acid superlubricity emphasizes the function of $\mathrm{H}^{+}$, which can promote protonation reactions and thus stern layer formation. Luo et al. [47, 48] proposed the important contributions of electric double layer force to such liquid superlubricities. Therefore, superlubricity should be available in other solutions with these two features. It did not take long before superlubricity was achieved in a mixture of acid and glycerol [44], further proving the above theory.

The problem concerning acid-aided superlubricity is obvious-The presence of acid can easily cause corrosion. Fortunately, Ge et al. [51] proved that a similar superlubricity state can also be achieved under neutral conditions $(\mathrm{pH} \approx 6.4)$, when they added boric acid to a polyethylene glycol (PEG) aqueous solution, as shown in Fig. 4(b). A boron chelate complex is formed when boric acid reacts with PEG. The process can not only neutralize the solution but also continuously supply $\mathrm{H}^{+}$ions, which are essential for the running-in process. 

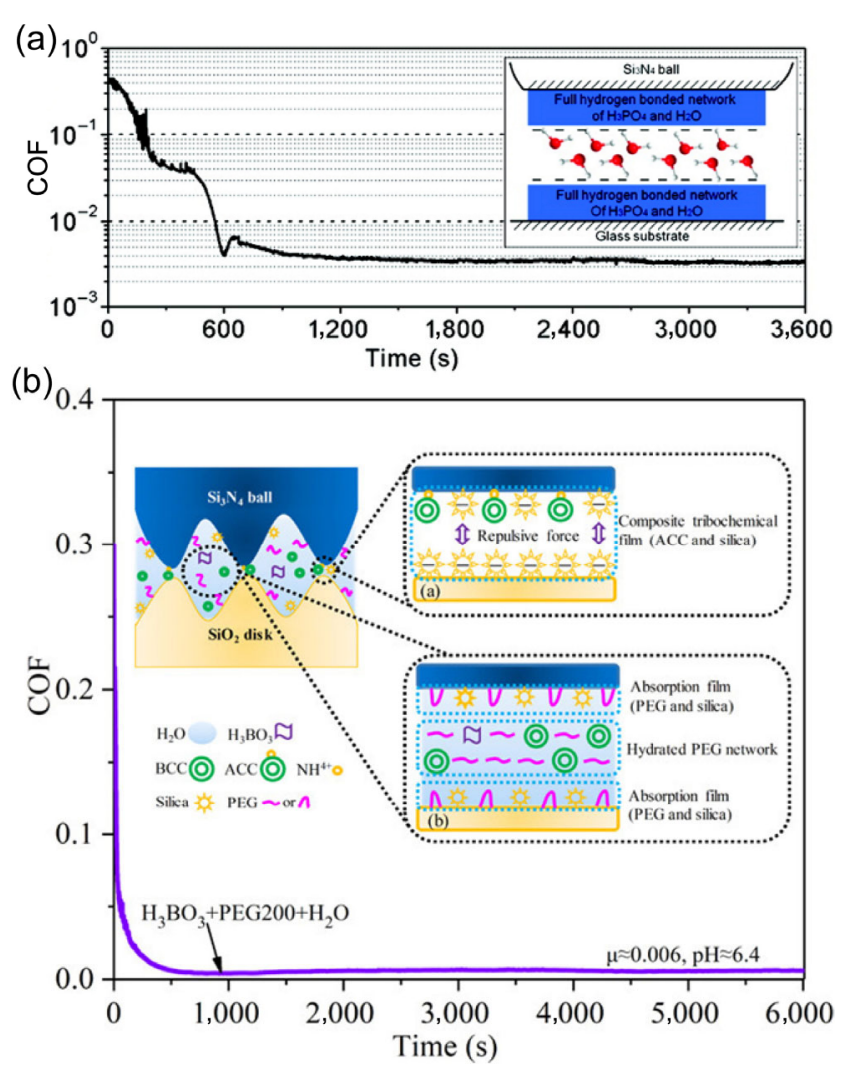

Fig. 4 (a) Superlubricity of phosphoric acid. The hydrogen-bond network can further induce the formation of a layer of hydrated water. Reproduced with permission from Ref. [43]. (C) American Chemical Society, 2011. (b) Superlubricity obtained under a neutral condition in the mixture of boric acid and PEG. Reproduced with permission from Ref. [51]. (C) American Chemical Society, 2018.

\subsubsection{Ionic liquids and hydrated ions}

Ionic liquids (ILs) are a group of representative lubricants and lubricating additives that can dramatically reduce friction and wear, and postpone corrosion and mechanical failure [52-54]. Recently, Ge et al. [55] checked the tribological performances of ILs, consisting of different cations and anions, together with ethylene glycol (EG) between ceramic surfaces. As shown in Fig. 5(a), three kinds of cations $\left(\mathrm{Li}^{+}, \mathrm{Na}^{+}\right.$, and $\left.\mathrm{K}^{+}\right)$and the same number of anions $\left(\mathrm{PF}_{4}^{-}, \mathrm{BF}_{4}^{-}\right.$, and $\left.\mathrm{NTf}_{2}^{-}\right)$were inspected, among which $[\mathrm{Li}(\mathrm{EG})] \mathrm{PF}_{6}$ exhibited the best superlubricity and anti-wear properties. It appears that the smaller size of monovalent metal cations is more beneficial for reducing wear. Moreover, $\mathrm{PF}_{4}{ }^{-}$ exhibits the best superlubricitive property because it can transform into phosphates, which act as outstanding lubricants, through tribochemical reactions.

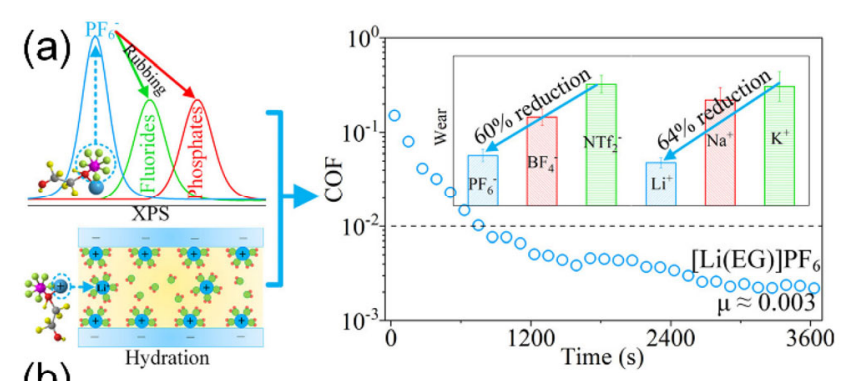

(b)
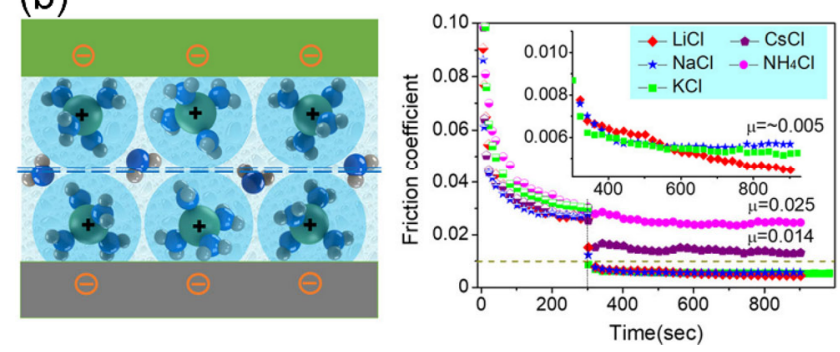

Fig. 5 (a) $[\mathrm{Li}(\mathrm{EG})] \mathrm{PF}_{6}$ can provide the best superlubricity among other combinations of anions and cations, because $\mathrm{Li}^{+}$is the smallest and $\mathrm{PF}_{6}{ }^{-}$can transform into phosphates. Reproduced with permission from Ref. [55]. (C) American Chemical Society, 2019. (b) Superlubricity obtained by hydrated alkali metal ions. Reproduced with permission from Ref. [56]. @ A American Chemical Society, 2018.

From previous clarification, it would appear that hydrated water is always contributory in various liquid superlubricity conditions. Han et al. [56] obtained macroscale superlubricity under high pressure between a $\mathrm{Si}_{3} \mathrm{~N}_{4}$ ball and a sapphire disk with the help of hydrated alkali metal ions. In the boundary lubrication state, hydration shells wrap the alkali metal ions like shields, as shown in Fig. 5(b). This supplies a hydration repulsive force to balance the large normal load, provides a fluid response to shear, and significantly reduces friction.

\subsubsection{Hydrodynamic effect}

From the above discussion, it is clear that realization of liquid superlubricity may need the help of various substances such as acid or 2D materials. The system is usually under a boundary lubrication (BL), thin film lubrication (TFL) or mixed lubrication (ML) state, and in such cases the effect of hydrodynamic lubrication is relatively negligible, especially when the focus is on the nanoscale effects and surface interactions [57]. However, for liquid lubrication, we cannot just skip the effect of hydrodynamic lubrication completely in TFL or ML state. This effect is more notable at the 
macroscale; hence, it may be more helpful from the perspective of industrial application. Deng et al. [49] used phosphoric acid to lubricate a tribo-pair consisting of a silicon nitride ball and a sapphire plate, and they found the lubrication regime changes from boundary lubrication to TFL and elastohydrodynamic lubrication (EHL) and achieved a superlubricity state with a COF of 0.003. Li et al. [58] found that silicon oil could form a hydrodynamic film under certain sliding speeds between $\mathrm{Si}_{3} \mathrm{~N}_{4}$ and glass. Long et al. [59] obtained a COF of 0.004 between a steel ball and an amorphous DLC coating in glycerol lubrication. They claimed that the formation of iron oxy-hydroxide on the sliding surfaces together with glycerol could result in a polishing process and thus helped with obtaining a self-sustained EHL regime.

\subsection{Solid-liquid combined superlubricity (SLCS)}

2D materials acting as good materials for solid superlubricity [60] also can be added into liquids to form a system of solid-liquid combined superlubricity (SLCS). The main characteristic functioning in this context is their low shearing strength, which makes it easier for interlayer sliding to take place. By adding graphene-oxide (GO) nanosheets into IL ([Li(EG)] $\mathrm{PF}_{6}$ ), superlubricity can be achieved on a $\mathrm{Si}_{3} \mathrm{~N}_{4}$ /sapphire interface under a pressure of $600 \mathrm{MPa}$. Surface characterization indicates that GO nanoflakes are absorbed on the wear surface, which can sustain a high load and meanwhile prevent asperities from probable reactions. The exceedingly low shear stress on the GO nanosheet interlayers also plays a crucial role in maintaining superlubricity [61], as shown in Fig. 6(a). A similar process can also occur in polyalkylene glycol (PAG) aqueous solutions with ultrathin layered double hydroxide nanosheets (ULDH-NS), in which case the absorption of the ULDH-NS on the solid surface can flatten, polish, and protect the contact zone because of the relatively low interlayer interaction of ULDH-NS. The presence of ULDH-NS can also benefit the absorption of PAG molecules, guaranteeing fluid lubrication [62].

2D material additives can also bring more than just low shear stress. As shown in Fig. 6(b), Wang et al. [63] used black phosphorus (BP) as an additive and achieved a very low COF of 0.0006 . $\mathrm{NaOH}$-modified
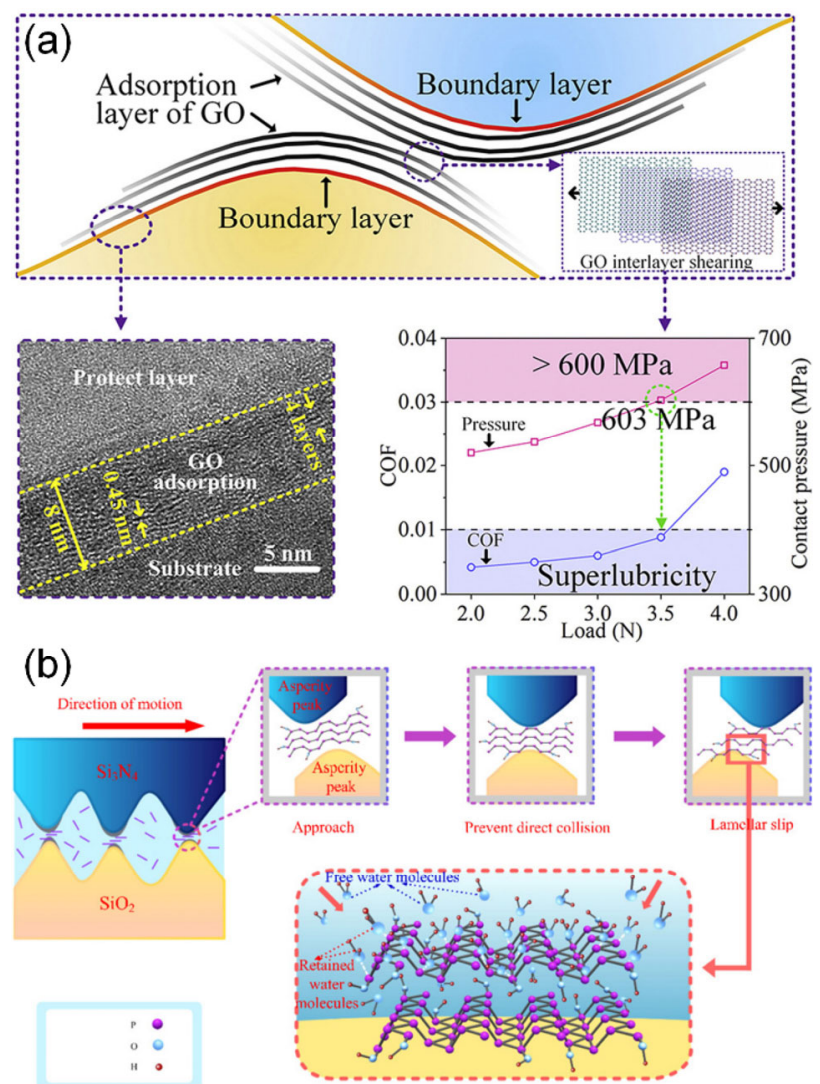

Fig. 6 (a) Superlubricity achieved under high pressure with a mixture of $\mathrm{GO}$ and $[\mathrm{Li}(\mathrm{EG})] \mathrm{PF}_{6}$; here GO provides protection for the surface, as well as low interlayer shear resistance. Reproduced with permission from Ref. [61]. (C) Elsevier Ltd., 2019. (b) Superlubricity realized by using $\mathrm{BP}$ as an additive. In this condition, the water layer captured by $\mathrm{BP}-\mathrm{OH}$ is the main reason for friction reduction. Reproduced with permission from Ref. [63]. (C) American Chemical Society, 2018.

ultrafine BP nanosheets (BP-OH) can be observed under various working conditions, and the presence of $\mathrm{BP}-\mathrm{OH}$ is conducive to capturing water molecules to form a water layer with low shear resistance that can sustain contact pressure to $1 \mathrm{GPa}$. Li et al. [64] found that interaction between water molecules and graphene is low, resulting in a low energy barrier for water sliding against the graphene surface. When a micro-ball coated with self-assembled fluoroalkyl monolayers (which can provide a highly hydrophobic surface) is forced to slide on a graphene surface in water, a nanometer-thick water layer is intercalated into the interface and thus generates superlubricity. It is also found that GO nanoflakes (GONFs) can interact with ethane diol (EDO) through hydrogen bonding to form hydrated GONFs-EDO networks, 
which is the main reason for friction reduction in those areas not covered by absorbed GONFs [61].

\section{Superlubricity and engineering}

Friction causes a very big number of economic waste per year in the world. Superlubricity can decrease COF values by orders of magnitude, eventually reaching COF values of $\sim 0.0001$ to 0.001 . In existing machines, the COF is usually 0.05-0.1. Therefore, if superlubricitive technologies can be applied to $10 \%-20 \%$ of the current industrial components, $300-500$ billion USD of economic benefit might be obtained per year because of less energy consumption. Moreover, superlubricity can also lead to less frictional heat, which will vastly reduce the failure of lubricating fluids. Approximately 40 million tons of lubricating oil is consumed worldwide per year, at a cost of 200 billion USD. If superlubricitive technologies can be applied in this area, the lifetime of lubricating fluids can be lengthened by $20 \%$, which can bring 40 billion USD of economic benefit per year. Moreover, superlubricity can also reduce wear substantially, bringing the wear rate close to zero. Worldwide wear loss itself takes $\sim 2 \%$ of the world's GDP, representing an economic loss of 1.7 trillion USD in 2018. This means that superlubricitive engineering to reduce wear can also bring huge benefits. What's more, longer device lifetime and less frictional energy consumption and wear can not only further reduce the cost of waste disposal (thus helping improve running efficiency and decrease the running cost of the whole industry), but also help ameliorate problems such as noise and environmental pollution. In other words, large-scale application of superlubricity may result in trillions of dollars of economic benefits a year in the world.

\subsection{Transportation}

In the era of globalization, transportation, which moves people, materials, and products around the world, is perhaps the most important economic sector. According to a report by Holmberg and Erdemir [3], 30\% of the energy consumed by various vehicles is used to overcome friction, among which $10 \%$ is lost because of wear. Utilization of various tribological techniques can save $\sim 25 \%$ of the energy in the short term [65]. In this part, we discuss several different categories of common vehicles, but first we start with the important origin of frictional loss-Transmission pieces.

\subsubsection{Transmission pieces}

Transmission appliances, such as gearboxes, bearings, and clutches, are one of the main contributors to frictional energy loss in all kinds of vehicles, as well as in other mechanical devices and electromechanical products. Their usage is quite widespread, thus a significant economic effect can be achieved if superlubricity technologies can be introduced into these devices. Here we take the most common components (the gearboxes and bearings) as examples.

\subsubsection{Gearboxes}

The global output value of gearboxes, as shown in Fig. 7(a), has been increasing in the past five years, and it will surpass 140 billion USD in 2019. It is expected to exceed 160 billion USD by 2025 .

In 2018, the total output value of the Chinese gearbox market was $\sim 39,742$ million USD, ranking first in the world. As shown in Fig. 7(b), about 94.03\% of all industrial gearboxes are used in the automotive
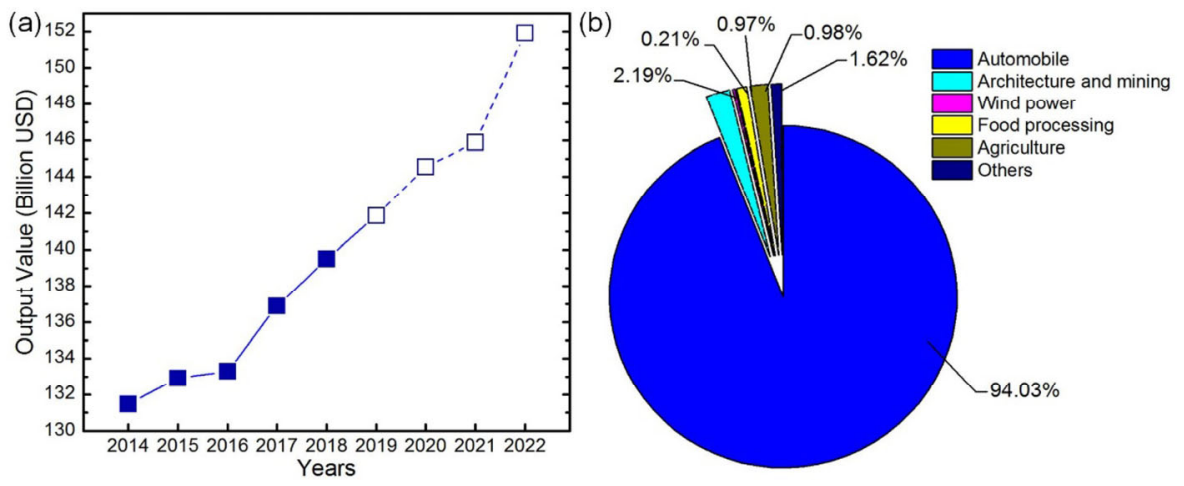

Fig. 7 (a) Global gearbox output value and (b) distribution of production quantities of gearboxes in different fields. 
industry; other consumption areas include construction and mining, wind electricity, and agricultural machinery, among which, wind electricity will become the main contributor to increases in the future. These devices require gearboxes and gears with greater accuracy, reliability, and transmission efficiency, as well as longer lifetimes.

There are various kinds of gearboxes, as shown in Table 1 . Though they may have different features and performance characteristics, they all suffer from wear failure of teeth because of friction, as shown in Fig. 8. Lubrication is the main solution to this problem. It influences mechanical efficiency, fatigue, and gear dynamics [66]. Relevant researches have focused on the influence of different types of lubricants and additives [67, 68], the lubrication regime [69], and other factors. If superlubricity technologies can be utilized to optimize the manufacturing of gearboxes, as well as be used during running, these problems can be solved more effectively. Though industrial realization may take some time, work on lubricants capable of realizing superlubricity for gears has progressed steadily [70, 71].

\subsubsection{Bearings}

In the field of bearings, worldwide business income has increased significantly over the past decade and reached 80 billion USD in 2017. The overall demand for bearing products in Chinese market in 2017 was $\sim 17.5$ billion USD, accounting for $22 \%$ of the world market. The income of main bearing companies above the designated scale also increases worldwide, e.g., in

Table 1 Comparison of main technical features of gearboxes.

\begin{tabular}{cccc}
\hline Item & Rotate vector (RV) & Harmonic driving & Planetary \\
\hline Volume/height & Heavy & Small & Small \\
Transmission ratio per stage & $31-171$ & $70-320$ & $6-500$ \\
Engagement & Multi-tooth & Multi-tooth & No multi-tooth \\
Bearing capacity & Large & Ordinary & Relatively large \\
Torsional rigidity & Large & Small & Large \\
Transmission accuracy & High & High & Low \\
Return difference & Small & Small & Big \\
Efficiency & $80 \%-90 \%$ & $60 \%-85 \%$ & $60 \%-85 \%$ \\
Lifetime & Long & Relatively long & Long \\
Advantages \& & Complex structure, difficult & Compatible with flexible gears & and flexible bearings, easy \\
disadvantages & manufacture, and high cost & gears or flexible bearings, and & high reliability \\
\hline
\end{tabular}

(a)

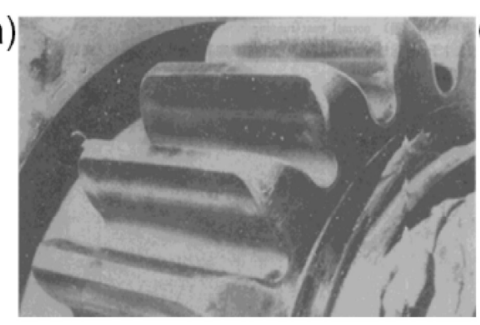

(c)

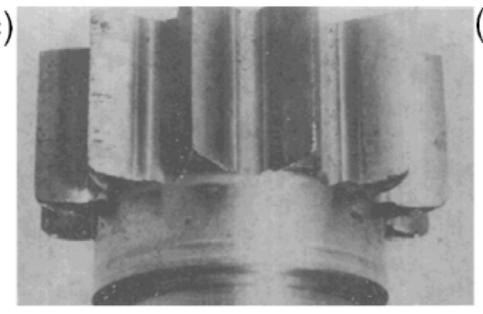

(b)

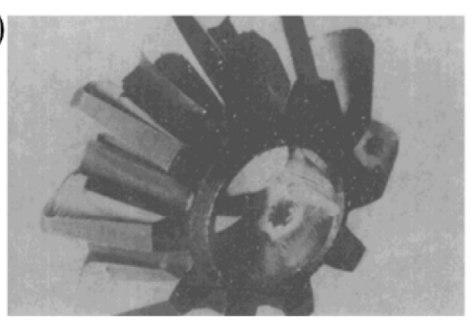

(d)

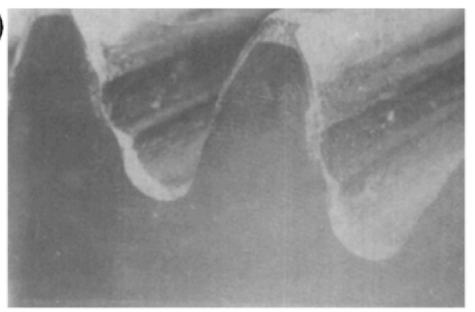

Fig. 8 Various kinds of gear teeth wear [72]: (a) moderate wear, (b) polishing, (c) abrasive wear, and (d) interference wear. 
China it has increased by $48 \%$ from 2010 to 2018 and is up to 185 billion RMB yuan (or 26.4 billion USD) in 2018, as shown in Fig. 9. However, the United States occupies the biggest market proportion of main bearing-demanding regions in the world, since the biggest proportion of bearings sold to different fields is the automotive industry, as shown in Fig. 10. For such huge market, even though modern bearings have tended to be perfect since their invention in 1760, how to improve its lifetime and reduce the friction energy consumption during its operation is still an important problem. The lifetime of bearings is mainly limited by fatigue and wear of the moving parts, and many major accidents occur because of the wear failure of bearings. Consequently, it is vital to provide reliable lubrication to maintain the function of bearings.

Superlubricity can be helpful in solving the problem of wear, especially in sliding bearings and joint bearings. Superlubricity has been achieved in rolling/ sliding contacts $[73,74]$, which is similar to the real working condition of various bearings. Elevating efficiency, accuracy, and reliability is an inexorable developing trend for all kinds of bearings, and superlubricitive engineering can act as a powerful weapon to achieve that goal.

\subsubsection{Automotive industry}

The automotive industry is one of the most important pillars in modern industry, and frictional phenomena in vehicles are quite representative. Under the current context in which traditional energy sources are facing probable shortage, ameliorating energy losses in various vehicles become essential. According to calculations, in typical vehicles such as passenger cars, trucks, and buses, approximately one-third of the fuel energy is consumed to overcome friction in engines, drivetrains, tires, and brakes. Apart from the necessary consumption in brakes, $28 \%$ of the fuel (a)

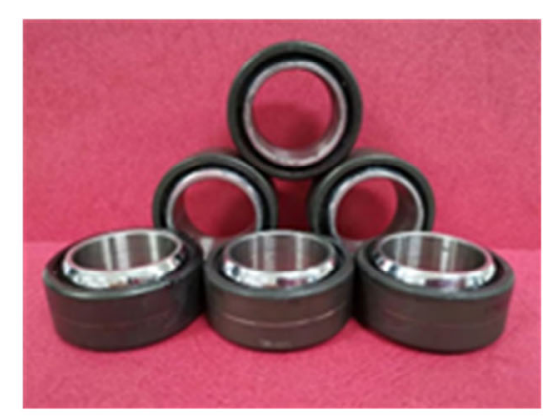

(b)

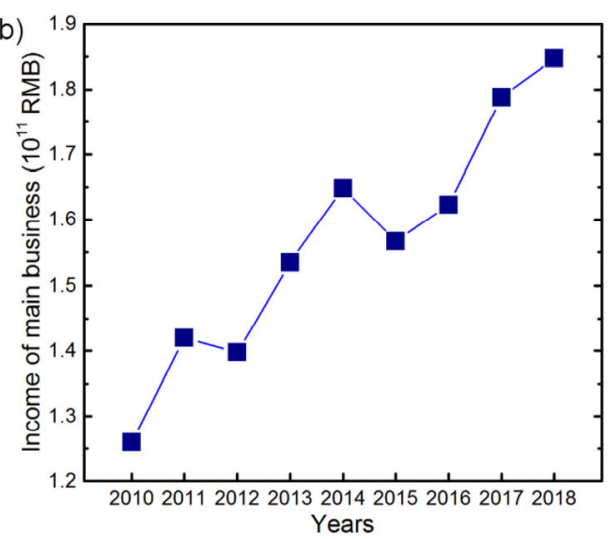

Fig. 9 (a) Solid lubricated joint bearing and (b) income of principal bearing companies above the designated scale in China from 2010 to 2018 .

(a)

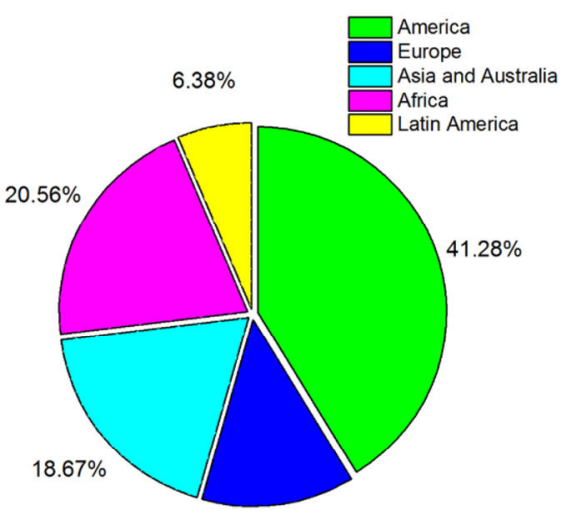

$13.11 \%$

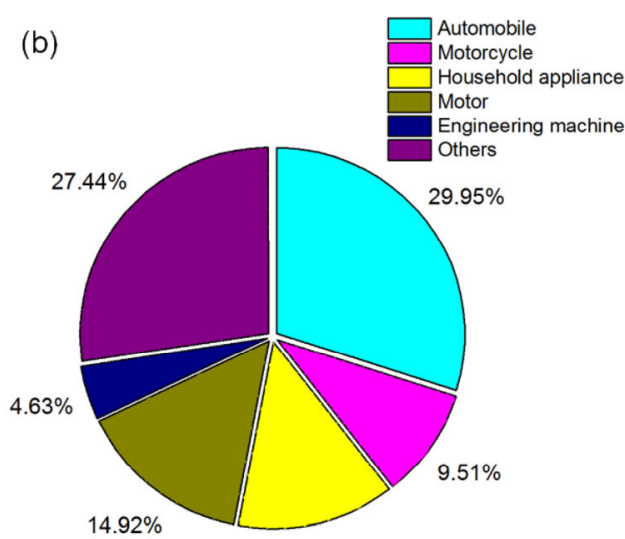

$13.55 \%$

Fig. 10 (a) Market proportion of main bearing-demanding regions in the world and (b) proportion of bearings sold to different fields. 
energy in passenger cars $(26 \%$ in the case of heavyduty vehicles such as trucks or buses) is lost because of friction and parasitic consumption, which will cost the world 208 billion liters of fuel (with 180 billion liters in the case of heavy-duty vehicles) [65, 75]. Energy loss in the engine constitutes the main part of frictioninduced energy losses, accounting for $\sim 70 \%$, with piston packs playing the most important role $(\sim 40 \%-60 \%)$, followed by bearings and valves [76, 77].

Introducing various tribological methods into a vehicle's mechanical system may reduce friction losses by up to $61 \%$ in the long term. This can save the world $\sim 585$ billion liters of diesel fuel and reduce $\mathrm{CO}_{2}$ emission by 1,490 million tons per year $[65,75]$, while offering huge economic benefits [78]. Common strategies that have been proved to be effective include applying additives to the lubricating oil or to the fuel itself [79-82], and adding textures [83, 84] or coatings $[85,86]$ on surfaces of mechanical components. Comprehensive application of these different methods is also helpful [87]. It is believed that the introduction of superlubricity technologies can further reduce friction losses in vehicles.

\subsubsection{Trains}

Trains can be classified into heavy-duty and passenger trains, both of which are important for modern society and industry. The running speed of trains keeps increasing, and that of wheel-rail high-speed trains are presented in Table 2. There are also many experimental lines in the world testing the potential quality of high-speed trains, among which the highest speed (obtained in France) is $574.8 \mathrm{~km} / \mathrm{h}$, as shown in Fig. 11. Higher speed undoubtedly makes the condition of friction and wear worse.

The Chinese railway system is now developing at a quite fast pace. The total length is expected to be

Table 2 Running speed of wheel-rail high-speed trains in the world.

\begin{tabular}{ccc}
\hline Country & Kilometrage $(\mathrm{km})$ & Running speed $(\mathrm{km} / \mathrm{h})$ \\
\hline Japan & 3,040 & 320 \\
France & 2,647 & 320 \\
Germany & 3,038 & 300 \\
Italy & 1,350 & 300 \\
Spain & 3,100 & 310 \\
China & $>30,000$ & 350 \\
\hline
\end{tabular}

(a)
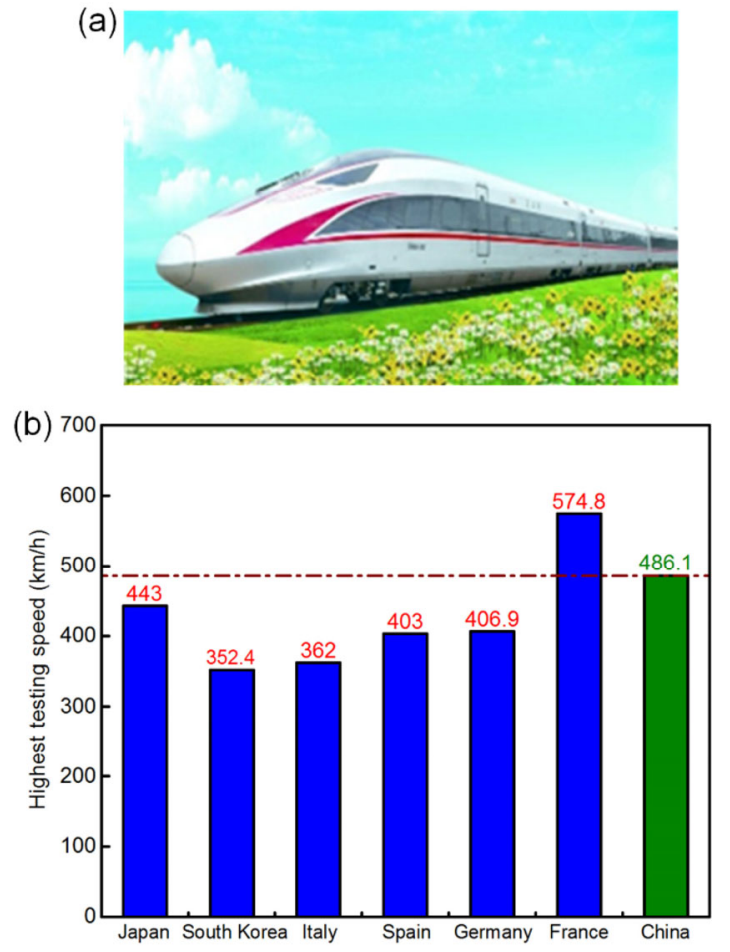

Fig. 11 (a) China Railway High-speed train. (b) Highest testing speed of high-speed trains in different countries.

$175,000 \mathrm{~km}$ by 2025 , with $38,000 \mathrm{~km}$ being high-speed railway. There are now a series of new railway lines under discussion, as shown in Fig. 12, and we hope that the world will be connected by high-speed rails, which will be the gospel for tourism. However, bearings in shaft boxes, gearboxes, and motors in high-speed trains face numerous problems brought by friction. For example, frictional heat leads to the failure of lubricating grease, and impulsive load aggravates wear.

When a train is running at high speed, wear of both the wheels and the rail will be intensified. Wear

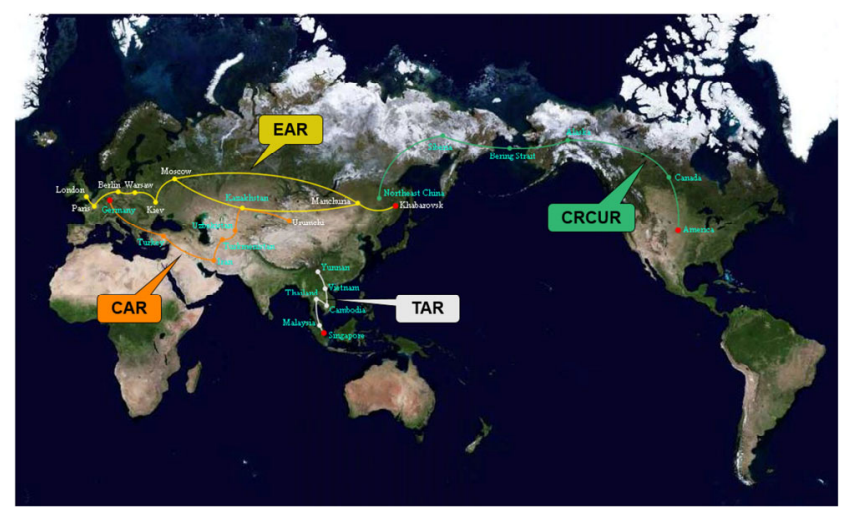

Fig. 12 Potential future railway lines under discussion. 
of the wheels under high speed will further lead to structural deformation, as shown in Fig. 13. When the running speed reaches $300 \mathrm{~km} / \mathrm{h}$, the dynamic load between the wheels and the rail equivalently increases by a factor of $\sim 10$, leading to an oscillation at $500-600 \mathrm{~Hz}$, which can damage bearings, gears, and other transmission components. Such a situation further intensifies wear and may even lead to lubrication failure. How to make full use of the near-zero friction and wear provided by superlubricity to solve these problems in transmission components in high-speed trains has been the key aspect of current research.

Meanwhile, development of heavy-duty trains for freight mainly focuses on the combination of larger carrying capacity and higher running speeds. The performances of different heavy-duty trains in the world are listed in Table 3. The main features of heavy-duty trains are the large amount of cabins and increasing axle load, both of which lead to severe wear. In North America, the lifetime of straight heavyduty railway track is $600-700$ million tons of freight transport, and the lifetime of curved track is only

(a)

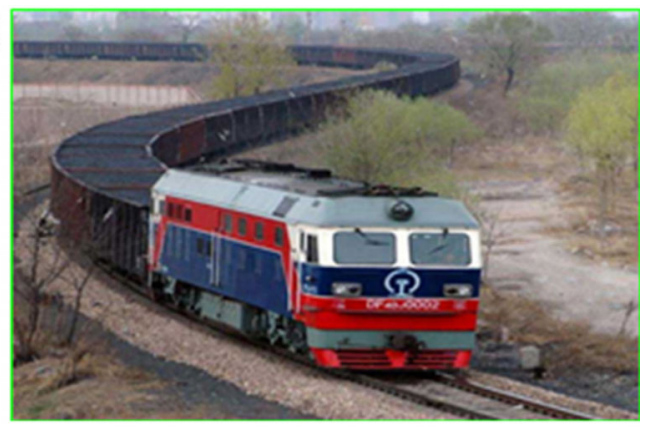

(b)

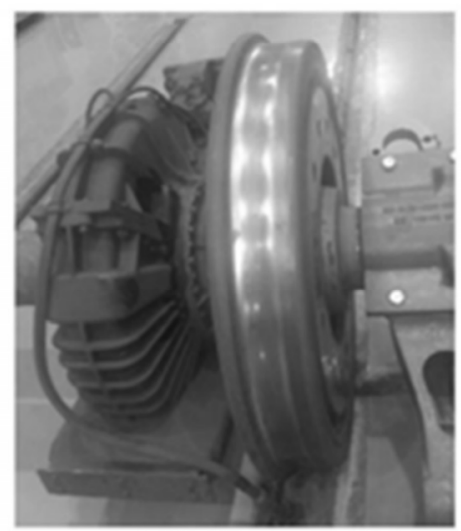

Fig. 13 Photographs of (a) a heavy-duty train and (b) an out-ofround high-speed train wheel. Reproduced with permission from Ref. [88]. (C) SAGE Publications, 2016.
125-300 million tons because of more severe wear. As mentioned above, higher running speed is one of the developing areas for heavy-duty trains. However, when the speed is enhanced to $200 \mathrm{~km} / \mathrm{h}$, the vibrational impact on transmission components will become very high, making realization of stable lubrication a very challenging issue. If superlubricity technologies can be introduced into these train systems, such dilemma may be relieved and thus significant economic benefits can be obtained.

\subsubsection{Aviation}

Airplanes are necessary because of their high speed. In upcoming years, the airplane industry will develop quickly in China, Russia, Brazil, and Israel. As shown in Fig. 14, the number of planes in China has been growing since 2012, as has the volume of circular flow. The output value of plane-related components is estimated to be over 25 billion RMB in 2018 in China. The worldwide market can be much larger.

The working conditions of planes are quite severe, with complicated external loads, small spaces, extreme temperature differences, low air pressure, vibrations, and other harsh conditions. These conditions will increase friction and lead to high frictional heat and wear, as well as noise and deformation. Approximately $25 \%$ of problems in flight safety are caused by failure of transmission agents such as gears and actuators. In China, aircraft repairs cost $>120$ billion RMB per year. Maintaining stable lubrication is key to alleviating problems caused by friction and wear in various components, resulting in notable savings in resources, and superlubricitive engineering is a promising choice to realize that goal.

Table 3 Different heavy-duty trains in the world.

\begin{tabular}{ccccc}
\hline Country & $\begin{array}{c}\text { Axle load } \\
(\mathrm{t})\end{array}$ & $\begin{array}{c}\text { Traction } \\
\text { ability (ten } \\
\text { thousand tons) }\end{array}$ & $\begin{array}{c}\text { Marshalling } \\
\text { (numbers } \\
\text { of cabins) }\end{array}$ & $\begin{array}{c}\text { Speed } \\
(\mathrm{km} / \mathrm{h})\end{array}$ \\
\hline America & $29.8-35.7$ & 2 & $130-150$ & $70-80$ \\
Australia & $25-40$ & 3 & $148-248$ & $70-80$ \\
Brazil & $25-32.5$ & 3.1 & $204-240$ & $60-75$ \\
$\begin{array}{c}\text { South } \\
\text { Africa }\end{array}$ & $26-30$ & 4.1 & 342 & $50-60$ \\
China & 25 & 2 & $108-216$ & $80-120$ \\
\hline
\end{tabular}


(a)

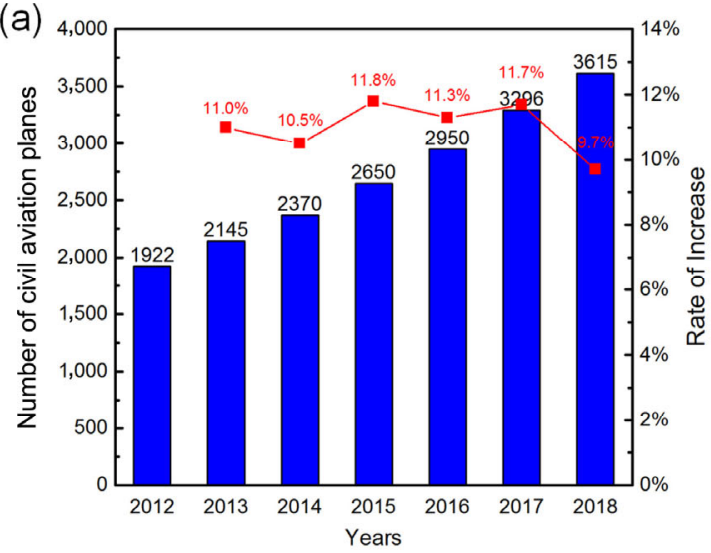

(b)

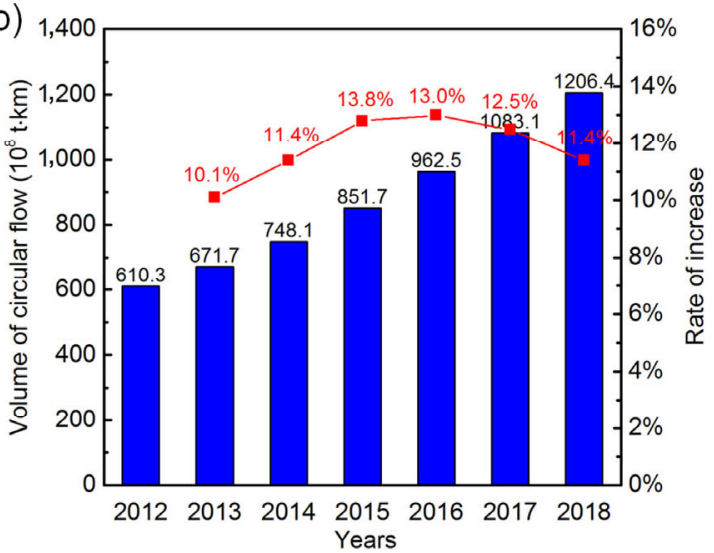

Fig. 14 (a) Numbers of civil aviation planes and (b) volume of circular flow in China [89].

\subsubsection{Watercraft}

Currently, the world's shipping industry has come into a period of low growth. New orders for shipping capacity in 2018 comprised 76.85 million deadweight tons (DWT), and the amount of completed shipbuilding was 80.12 million DWT. Up to the first half of 2019, the total capacity of the global shipping industry was 1.97 billion tons, which is in a state of oversupply. The capacity changes of different kinds of ships from 1996 to 2018 are shown in Fig. 15.

The shipping industry consumes 247-325 million tons of fuel per year in the world, resulting in a huge

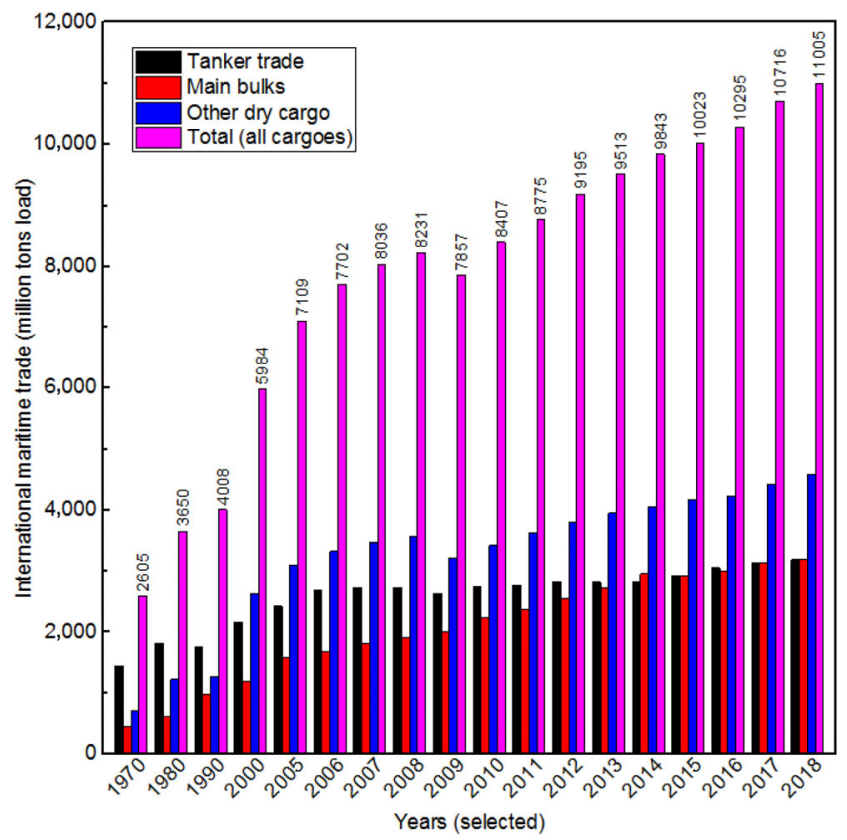

Fig. 15 Development in international maritime trade in selected years [90]. amount of pollutant emissions. $\mathrm{CO}_{2}$ emission by global maritime transport accounts for $2.8 \%$ of overall $\mathrm{CO}_{2}$ emission; for $\mathrm{NO}_{x}$ and $\mathrm{SO}_{x}$, the percentages are $\sim 15 \%$ and $\sim 13 \%$, respectively. The shipping industry also consumes 2.5 million tons of lubrication oil each year. Within this consumption, yearly demand for marine cylinder oil is $\sim 1.25$ million tons, representing $~ 50 \%$ of ship lubrication oil, while yearly demand for lubrication system oil is $\sim 875,000$ tons, representing $35 \%$. For a single ship, the cost of oil represents only $10 \%$ of the cost within its whole lifetime, with $90 \%$ being additional fuel consumption. Consequently, saving fuel is very important for ship owners.

Application of superlubricity technologies in the shipping industry will reduce not only friction and wear in the engine cylinder but also oil consumption. Moreover, application of superlubricity on ships' surfaces may help reduce sailing resistance, which can also bring economic benefits.

\subsection{Fluid machinery}

There are two kinds of fluid machines. One turns the fluid's energy into mechanical energy and is thus called a prime motor (e.g., water and steam turbines); the other turns mechanical energy into energy held by fluids in working machines (e.g., pumps and compressors). Fluid machinery is used in the fields of hydraulic, pneumatic, and sealing industries. The total industrial production value in China surpassed 100 billion RMB (14.28 billion USD) in 2016, and this value is still increasing at a rate of $5 \%$ per year. Many problems concerning friction and lubrication exist in 
the power elements, executing components, controlling units, and auxiliary components of these machines. Superlubricity can be applied in these components, for example, in gear pumps, plunger pumps, and other kinds of pumps, various valves, hydraulic cylinders, hydraulic motors, and so on.

\subsection{Manufacturing}

Manufacturing is the decisive step in all industries. In traditional machining, where material is removed from items, very high contact pressure and high speed between tools and work pieces are unavoidable, resulting in severe frictional heat generation and plastic deformation [91]. About 99\% of the energy supplied to the machine tool transforms into heat; high friction and the resultant high working temperature also lead to fast wear or even failure of the machine tools, as well as lower surface quality of the products [92].

The main strategy to solve the above dilemma is to use cutting fluid, which can act as both lubricant and coolant $[93,94]$. However, this is more of an expediency. Usage of cutting fluids only plays a limited role in restricting energy lost during manufacturing, but many components in cutting fluids can be harmful to human health and the environment. Application of cutting fluids also constitutes a heavy economic burden: According to statistics, $\sim 16 \%-20 \%$ of the production cost in the manufacturing industry is spent on cutting fluids [92, 95], amounting to billions of USD, and that does not yet include the cost to treat wastes.

Many new techniques have been developed to reduce the use of cutting fluids or to provide other approaches to reduce friction and wear directly. Minimum quantity lubrication technology is a typical method. Its goal is to replace the traditional flood cooling manner with feeding a mixture of compressed air and a relatively small amount of cutting fluid $[92,96]$. Stability and thermal conductivity can be significantly enhanced if various kinds of nanoparticles are added to the cutting fluid; these can help improve machining conditions and extend tool lifetime [97]. Constructing surface textures on tools can also help reduce friction and wear. In some cases, these can reduce or even eliminate the need to use cutting fluids. When a limited quantity of liquid or solid lubricants is filled into the texture, the anti-wear and cutting performance of tools can be even better [98, 99]. Astute readers may recognize that the latter two methods are to some extent similar to the methodology one may utilize to realize liquid or solid state superlubricity. We believe that by introducing more superlubricity technologies and ideas into manufacturing, considerable energy savings, as well as huge economic benefits, can be achieved.

\subsection{Space technologies}

The great Age of Discovery changed human history fundamentally to some extent, making great contributions to our culture and economy. As space technologies develop and evolve rapidly, we are now able to look forward to a new Age of Exploration, targeting outer space [100]. Such discovery relies on various spacecraft spacecrafts.

Spacecrafts contain different kinds of friction pairs in components such as bearings, wheel shafts, and sleeves. The essential distinction is that these friction pairs must work under extreme conditions - In vacuum with a wide temperature variation from $-200{ }^{\circ} \mathrm{C}$ to $200{ }^{\circ} \mathrm{C}$. In such conditions, traditional lubrication methods using oils or other liquid substances become nonviable or can only be used in space capsules. Furthermore, the lack of heat transfer media, cosmic radiation, and the solar wind complicates the situation even more. The existence of friction in kinematic pairs not only has a negative influence on spacecraft lifetime and reliability but also complicates the design procedure. Reducing the impact of frictional torque on a reaction wheel's attitude-adjustment function to obtain better control accuracy requires complex algorithms to compensate for the effect of friction [101-103]. There are also cases in which antennas fail to deploy because of friction [104].

Superlubricitive engineering may provide a new perspective in solving the above problems. It has been proved that materials that can help realize superlubricity, e.g., DLC, graphene, and $\mathrm{MoS}_{2}$ can tremendously reduce friction and wear under vacuum conditions [105] or a simulated space environment [106]. However, the main challenge is to find a better strategy to handle the multiple severe working conditions in order to enhance the stability and lifetime 
of lubrication coatings. New kinds of materials that can provide both superlubricity and enough hardness, thermal stability, and oxidation resistance still need to be explored. Attention paid to harder materials such as titanium nitride (TiN) [107] can be taken as a good attempt.

\subsection{Microelectromechanical systems}

Microelectromechanical systems (MEMS) have undoubtedly provided the whole industry with greater possibilities by vastly shrinking the size of mechanical structures. Such shrinkage, though, comes with a price, because the simultaneous increase of surface area-tovolume ratio makes friction a critical restriction to an actuator's executing efficiency [108]. The value of friction and other interfacial interactions may be even close to the total driving forces of the devices, resulting in a sharp decline in lifetime or even failure of moving pairs. At the microscale, traditional methods for lubrication or wear resistance may not be effective; i.e., the viscosity effect is too remarkable if normal liquid lubrication is applied, and coatings might be too thick to be used at such a small scale [109].

To address this friction problem, various strategies have been developed, such as surface chemical and

(a)

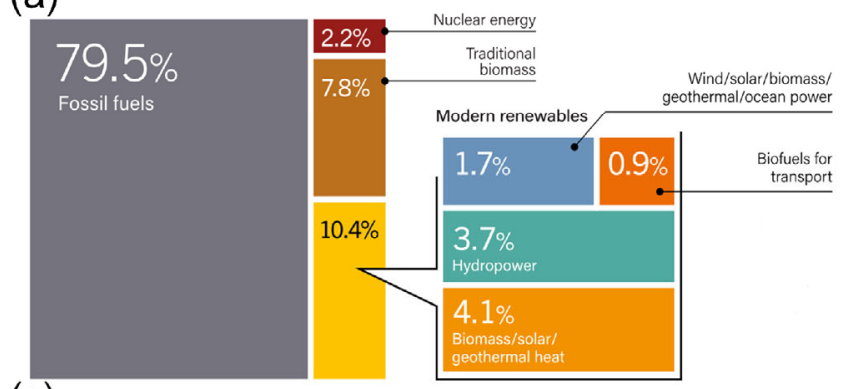

(c)

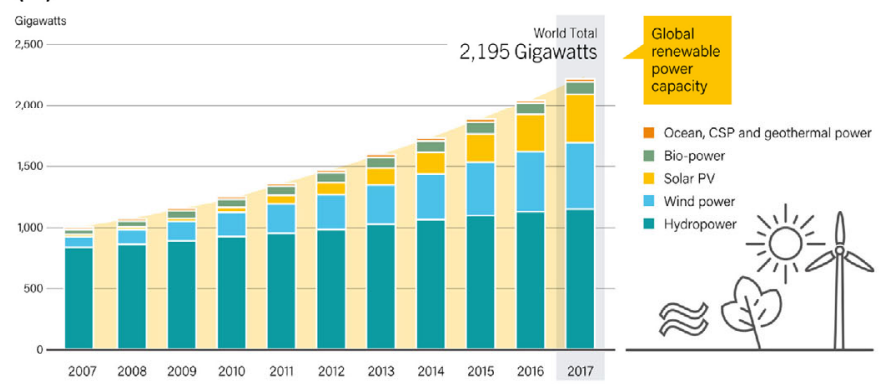

(d)
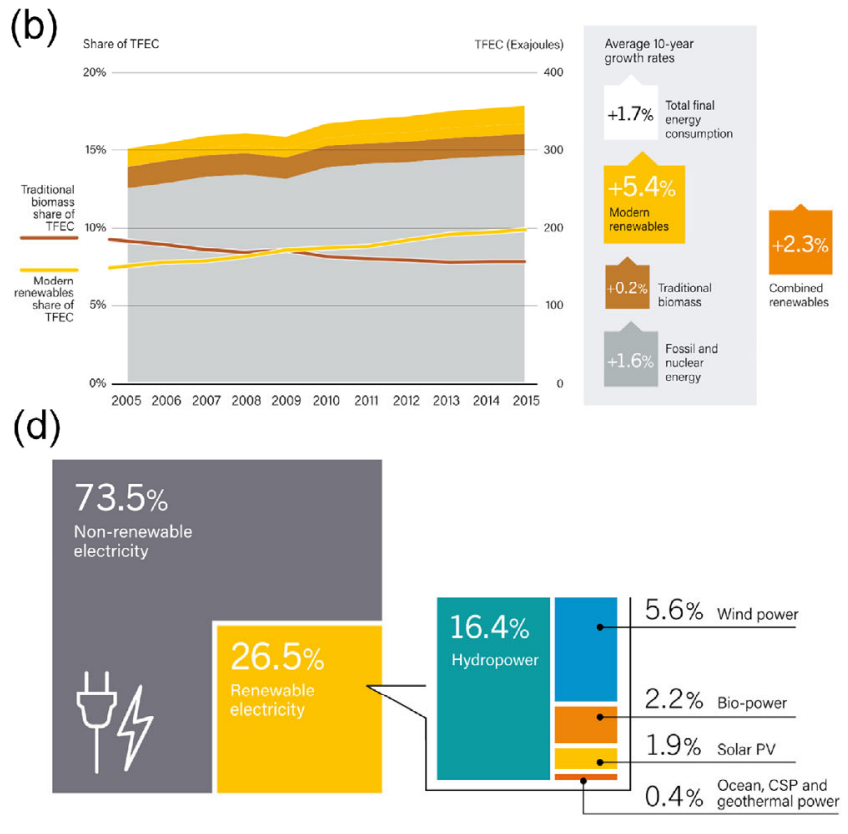

Fig. 16 (a) Estimated share of renewable energy in total final energy consumption in 2016; (b) increase of worldwide renewable energy in comparison to total final energy consumption from 2005 to 2015; (c) global renewable power capacity from 2007 to 2017; and (d) estimated share of renewable energy in global electricity production at the end of 2017 [113]. 
parts, including gears, bearings, and blades, is one of the key factors that shorten the lifetime of power generators and thus confines their economic benefit and feasibility [114, 115].

To apply various superlubricity technologies to address the above problem, some other factors must be considered, because items such as turbines also work under quite complex and harsh environments. For example, turbines for generating power from marine currents may face chemical or biological corrosion, cavitation, or poor contact situations because of the existence of small particles such as sand [116].

Besides, the main problem faced by gears in turbines is how to improve quality, stability, lifetime, and reliability. Gears often fail before the mainframe because of tooth wear. As shown in Fig. 17, gear tooth damage is a relatively large proportion of damage. The load on the wind power gearbox varies greatly, especially during a system overload caused by extreme wind speed or turbulent conditions and as the result of changes in the instantaneous peak load caused by distance adjustment or mechanical braking. Although the instantaneous peak load does not play a major role in the whole operation cycle, it has a great impact on the damage of gears, especially the tooth surface. The planetary gear always bears two-way force during
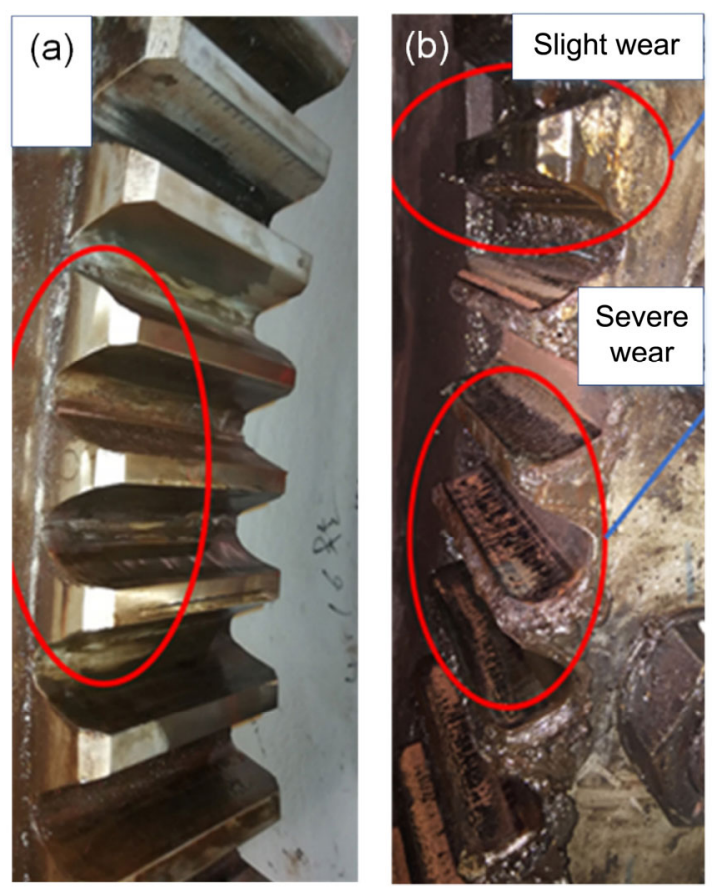

Fig. 17 Wear of gears in a wind turbine. its operation. Fatigue can occur and teeth can be broken because of the influence of gear accuracy and strength.

\subsection{Connection between laboratory research and industrial application}

This whole section is more of an outlook for future application of superlubricity than a comprehensive introduction to superlubricitive engineering. Seldom existing researches deal with real industrial working conditions directly, because there are still some problems that need to be solved. Here we try to list some of the key factors that restrict the application of superlubricity.

1) Scale: From what we have discussed above, most application scenarios are implemented at the macroscale. Although most liquid superlubricity research is performed at the macroscale, in some special situations (e.g., in space), solid superlubricity is necessary. However, some solid superlubricity systems, especially structural superlubricity, which usually needs the participation of 2D materials, can only be realized at the microscale. Research at the small scale is helpful to discover new mechanisms, but to move forward to application, more work needs to be conducted. Hod et al. [6] present a more detailed discussion concerning the issue of scale.

2) Carrying capacity: Real machines must do work, making loading a basic requirement. Many current researchers tend to avoid discussing the carrying capacity of their lubrication system. What is provided in most cases is only contact pressure or normal load under which superlubricity is realized. Even if we can equate contact pressure with carrying capacity, the maximum value we can obtain for the time being has just reached the magnitude of GPa, which may still be insufficient.

3) Stability: The main focus of current research is to obtain the state of superlubricity. Such a process usually must undergo a period of running-in, which will cause damage and wear to the tribo-pair. Even if that running-in process can be avoided, superlubricity can only be maintained within a limited time. The decay of superlubricity may be unavoidable, but a deeper understanding of the specific process and mechanism of such decay may help us lengthen the 
lifetime of superlubricity systems, which is quite vital for practical application.

4) Controllability: Although reduction of friction is welcome in most cases, there are also conditions in which friction is necessary or an adjustable COF is expected. Many works have already addressed the influence of various factors on superlubricity, but more precise control is yet to be realized.

\section{Conclusions}

A great improvement of superlubricity has been made from 2007 to 2019, with COF values changing from $10^{-3}$ to $10^{-4}$ for liquid superlubricity and reaching $10^{-5}$ for solid superlubricity. The measurement resolution of the COF can reach the level of $10^{-6}$ now. Superlubricity provides us with a powerful tool to handle energy issues by suppressing friction as much as possible to maximize energy savings. However, to transform scientific research into real applications, superlubricitive engineering must be developed. From the review of current experimental and theoretical results, we can already see the beginning of superlubricitive engineering, because researchers have been intentionally considering topics of importance to industry, but there is still a long way to go. Despite the challenges we are going to face, we believe that superlubricitive engineering will change the entire industries in terms of both ideas and methodologies. Until then, more efforts must be devoted to address various situations in each specific field.

\section{Acknowledgements}

This work is supported by the National Natural Science Foundation of China (No. 51527901).

Open Access This article is licensed under a Creative Commons Attribution 4.0 International Li-cense, which permits use, sharing, adaptation, distribution and reproduction in any medium or for-mat, as long as you give appropriate credit to the original author(s) and the source, provide a link to the Creative Commons licence, and indicate if changes were made.

The images or other third party material in this article are included in the article's Creative Commons licence, unless indicated otherwise in a credit line to the material. If material is not in-cluded in the article's Creative Commons licence and your intended use is not permitted by statutory regulation or exceeds the permitted use, you will need to obtain permission directly from the copyright holder.

To view a copy of this licence, visit http://creativecommons.org/licenses/by/4.0/.

\section{References}

[1] Dašić P, Franek F, Assenova E, Radovanovic M. International standardization and organizations in the field of tribology. Ind Lubr Tribol 55(6): 287-291 (2003)

[2] Jost H P. Tribology micro and macro economics: A road to economic savings. In World Tribology Congress III, Washington DC, 2005: 18-22.

[3] Holmberg K, Erdemir A. Influence of tribology on global energy consumption, costs and emissions. Friction 5(3): 263-284 (2017)

[4] Shinjo K, Hirano M. Dynamics of friction: Superlubric state. Surf Sci 283(1-3): 473-478 (1993)

[5] Erdemir A, Martin J M. Superlubricity. Amsterdam (The Netherlands): Elsevier, 2007.

[6] Hod O, Meyer E, Zheng Q S, Urbakh M. Structural superlubricity and ultralow friction across the length scales. Nature 563(7732): 485-492 (2018)

[7] Hod O. Interlayer commensurability and superlubricity in rigid layered materials. Phys Rev B 86(7): 075444 (2012)

[8] Liu S W, Wang H P, Xu Q, Ma T B, Yu G, Zhang C H, Geng D C, Yu Z W, Zhang S G, Wang W Z, et al. Robust microscale superlubricity under high contact pressure enabled by graphene-coated microsphere. Nat Commun 8(1): 14029 (2017)

[9] Erdemir A. Superlubricity and wearless sliding in diamondlike carbon films. MRS Online Proceeding Library 697: 9.1 (2001)

[10] Le Cao Ky D, Tran Khac B C, Le C T, Kim Y S, Chung K H. Friction characteristics of mechanically exfoliated and CVD-grown single-layer $\mathrm{MoS}_{2}$. Friction 6(4): 395-406 (2018)

[11] Novoselov K S, Jiang D, Schedin F, Booth T J, Khotkevich V V, Morozov S V, Geim A K. Two-dimensional atomic crystals. Proc Natl Acad Sci USA 102(30): 10451-10453 (2005)

[12] Martin J M, Donnet C, Le Mogne T, Epicier T. Superlubricity of molybdenum disulphide. Phys Rev B 48(14): 10583-10586 (1993)

[13] Dienwiebel M, Verhoeven G S, Pradeep N, Frenken J W M, Heimberg J A, Zandbergen H W. Superlubricity of graphite. Phys Rev Lett 92(12): 126101 (2004) 
[14] Li J J, Li J F, Luo J B. Superlubricity of graphite sliding against graphene nanoflake under ultrahigh contact pressure. Adv Sci 5(11): 1800810 (2018)

[15] Liu Y M, Song A S, Xu Z, Zong R L, Zhang J, Yang W Y, Wang R, Hu Y Z, Luo J B, Ma T B. Interlayer friction and superlubricity in single-crystalline contact enabled by twodimensional flake-wrapped atomic force microscope tips. ACS Nano 12(8): 7638-7646 (2018)

[16] Berman D, Erdemir A, Sumant A V. Approaches for achieving superlubricity in two-dimensional materials. ACS Nano 12(3): 2122-2137 (2018)

[17] Wang K Q, Ouyang W G, Cao W, Ma M, Zheng Q S. Robust superlubricity by strain engineering. Nanoscale 11(5): 21862193 (2019)

[18] Liu J, Qi Y Z, Li Q Y, Duan T Y, Yue W, Vadakkepatt A, Ye C, Dong Y L. Vacancy-controlled friction on 2D materials: Roughness, flexibility, and chemical reactions. Carbon 142: 363-372 (2019)

[19] Wang L F, Zhou X, Ma T B, Liu D M, Gao L, Li X, Zhang J, Hu Y Z, Wang H, Dai Y D, et al. Superlubricity of a graphene/ $\mathrm{MoS}_{2}$ heterostructure: A combined experimental and DFT study. Nanoscale 9(30): 10846-10853 (2017)

[20] Sun J H, Zhang Y N, Lu Z B, Li Q Y, Xue Q J, Du S Y, Pu J B, Wang L P. Superlubricity enabled by pressure-induced friction collapse. J Phys Chem Lett 9(10): 2554-2559 (2018)

[21] Sun J H, Chang K K, Mei D H, Lu Z B, Pu J B, Xue Q J, Huang Q, Wang L P, Du S Y. Mutual identification between the pressure-induced superlubricity and the image contrast inversion of carbon nanostructures from AFM technology. J Phys Chem Lett 10(7): 1498-1504 (2019)

[22] Song Y M, Mandelli D, Hod O, Urbakh M, Ma M, Zheng Q S. Robust microscale superlubricity in graphite/hexagonal boron nitride layered heterojunctions. Nat Mater 17(10): 894-899 (2018)

[23] Li J J, Ge X Y, Luo J B. Random occurrence of macroscale superlubricity of graphite enabled by tribo-transfer of multilayer graphene nanoflakes. Carbon 138: 154-160 (2018)

[24] Berman D, Narayanan B, Cherukara M J, Sankaranarayanan S K R S, Erdemir A, Zinovev A, Sumant A V. Operando tribochemical formation of onion-like-carbon leads to macroscale superlubricity. Nat Commun 9(1): 1164 (2018)

[25] Gong Z B, Jia X L, Ma W, Zhang B, Zhang J Y. Hierarchical structure graphitic-like/MoS film as superlubricity material. Appl Surf Sci 413: 381-386 (2017)

[26] Erdemir A, Eryilmaz O. Achieving superlubricity in DLC films by controlling bulk, surface, and tribochemistry. Friction 2(2): 140-155 (2014)
[27] Miyoshi K, Murakawa M, Watanabe S, Takeuchi S, Miyake S, Wu R L C. CVD diamond, DLC, and c-BN coatings for solid film lubrication. Tribol Lett 5(2-3): 123-129 (1998)

[28] Erdemir A. Design criteria for superlubricity in carbon films and related microstructures. Tribol Int 37(7): 577-583 (2004)

[29] Erdemir A. The role of hydrogen in tribological properties of diamond-like carbon films. Surf Coat Technol 146-147: 292-297 (2001)

[30] Zeng Q F, Eryilmaz O, Erdemir A. Superlubricity of the DLC films-related friction system at elevated temperature. Rsc Adv 5(113): 93147-93154 (2015)

[31] Chen X C, Zhang C H, Kato T, Yang X A, Wu S D, Wang R, Nosaka M, Luo J B. Evolution of tribo-induced interfacial nanostructures governing superlubricity in a-C:H and a-C:H:Si films. Nat Commun 8(1): 1675 (2017)

[32] Mutyala K C, Wu Y A, Erdemir A, Sumant A V. Graphene$\mathrm{MoS}_{2}$ ensembles to reduce friction and wear in DLC-Steel contacts. Carbon 146: 524-527 (2019)

[33] Liu Y H, Yu B J, Cao Z Y, Shi P F, Zhou N N, Zhang B, Zhang J Y, Qian L M. Probing superlubricity stability of hydrogenated diamond-like carbon film by varying sliding velocity. Appl Surf Sci 439: 976-982 (2018)

[34] Liu Y H, Chen L, Zhang B, Cao Z Y, Shi P F, Peng Y, Zhou N N, Zhang J Y, Qian L M. Key role of transfer layer in load dependence of friction on hydrogenated diamond-like carbon films in humid air and vacuum. Materials 12(9): 1550 (2019)

[35] Braceras I, Ibáñez I, Dominguez-Meister S, Velasco X, Brizuela M, Garmendia I. Electro-tribological properties of diamond like carbon coatings. Friction 8(2): 451-461(2019)

[36] Cui L C, Zhou H, Zhang K F, Lu Z B, Wang X R. Bias voltage dependence of superlubricity lifetime of hydrogenated amorphous carbon films in high vacuum. Tribol Int 117: 107-111 (2018)

[37] Gao M, Li H Y, Ma L R, Gao Y, Ma L W, Luo J B. Molecular behaviors in thin film lubrication-Part two: Direct observation of the molecular orientation near the solid surface. Friction 7(5): 479-488 (2019)

[38] Ma L R, Luo J B. Thin film lubrication in the past 20 years. Friction 4(4): 280-302 (2016)

[39] Luo J B, Wen S Z, Huang P. Thin film lubrication. Part I. Study on the transition between EHL and thin film lubrication using a relative optical interference intensity technique. Wear 194(1-2): 107-115 (1996)

[40] Ge X, Halmans T, Li J, Luo J. Molecular behaviors in thin film lubrication-Part three: Superlubricity attained by polar and nonpolar molecules. Friction 7(6):625-636 (2018) 
[41] Zhang S H, Qiao Y J, Liu Y H, Ma L R, Luo J B. Molecular behaviors in thin film lubrication-Part one: Film formation for different polarities of molecules. Friction 7(4): 372-387 (2019)

[42] Li J J, Ma L R, Zhang S H, Zhang C H, Liu Y H, Luo J B. Investigations on the mechanism of superlubricity achieved with phosphoric acid solution by direct observation. $J$ Appl Phys 114(11): 114901 (2013)

[43] Li J J, Zhang C H, Luo J B. Superlubricity behavior with phosphoric acid-water network induced by rubbing. Langmuir 27(15): 9413-9417 (2011)

[44] Li J J, Zhang C H, Ma L R, Liu Y H, Luo J B. Superlubricity achieved with mixtures of acids and glycerol. Langmuir 29(1): 271-275 (2013)

[45] Klein J, Kumacheva E, Mahalu D, Perahia D, Fetters L J. Reduction of frictional forces between solid surfaces bearing polymer brushes. Nature 370(6491): 634-636 (1994)

[46] Ma L R, Gaisinskaya-Kipnis A, Kampf N, Klein J. Origins of hydration lubrication. Nat Commun 6(1): 6060 (2015)

[47] Luo J B, Deng M M, Zhang C H. Advances in Superlubricity. Plenary Talk at ITS-IFToMM 2017, March 19-22, Jeju, Korea, (2017)

[48] Deng M M. Investigation of liquid superlubricity mechansim. Ph.D. thesis. Beijing (China): Tsinghua University, 2017.

[49] Deng M M, Zhang C H, Li J J, Ma L R, Luo J B. Hydrodynamic effect on the superlubricity of phosphoric acid between ceramic and sapphire. Friction 2(2): 173-181 (2014)

[50] Li J J, Zhang C H, Sun L, Lu X, Luo J B. Tribochemistry and superlubricity induced by hydrogen ions. Langmuir 28(45): 15816-15823 (2012)

[51] Ge X Y, Li J J, Zhang C H, Luo J B. Liquid superlubricity of polyethylene glycol aqueous solution achieved with boric acid additive. Langmuir 34(12): 3578-3587 (2018)

[52] Saurín N, Sanes J, Carrión F J, Bermúdez M D. Self-healing of abrasion damage on epoxy resin controlled by ionic liquid. RSC Adv 6(43): 37258-37264 (2016)

[53] Somers A E, Khemchandani B, Howlett P C, Sun J Z, MacFarlane D R, Forsyth M. Ionic liquids as antiwear additives in base oils: Influence of structure on miscibility and antiwear performance for steel on aluminum. ACS Appl Mater Interfaces 5(22): 11544-11553 (2013)

[54] Han M W, Espinosa-Marzal R M. Molecular mechanisms underlying lubrication by ionic liquids: Activated slip and flow. Lubricants 6(3): 64 (2018)

[55] Ge X Y, Li J J, Zhang C H, Liu Y H, Luo J B. Superlubricity and antiwear properties of in situ-formed ionic liquids at ceramic interfaces induced by tribochemical reactions. $A C S$ Appl Mater Interfaces 11(6): 6568-6574 (2019)

[56] Han T Y, Zhang C H, Luo J B. Macroscale superlubricity enabled by hydrated alkali metal ions. Langmuir 34(38): 11281-11291 (2018)

[57] Zhang S W, Zhang C H, Hu Y Z, Ma L R. Numerical simulation of mixed lubrication considering surface forces. Tribol Int 140: 105878 (2019)

[58] Li J J, Zhang C H, Deng M M, Luo J B. Superlubricity of silicone oil achieved between two surfaces by running-in with acid solution. $R S C A d v$ 5(39): 30861-30868 (2015)

[59] Long Y, De Barros Bouchet M I, Lubrecht T, Onodera T, Martin J M. Superlubricity of glycerol by self-sustained chemical polishing. Sci Rep 9(1): 6286 (2019)

[60] Choudhary S, Mungse H P, Khatri O P. Dispersion of alkylated graphene in organic solvents and its potential for lubrication applications. J Mater Chem 22(39): 21032-21039 (2012)

[61] Ge X Y, Li J J, Wang H D, Zhang C H, Liu Y H, Luo J B. Macroscale superlubricity under extreme pressure enabled by the combination of graphene-oxide nanosheets with ionic liquid. Carbon 151: 76-83 (2019)

[62] Wang H D, Liu Y H, Liu W R, Liu Y M, Wang K P, Li J J, Ma T B, Eryilmaz O L, Shi Y J, Erdemir A, et al. Superlubricity of polyalkylene glycol aqueous solutions enabled by ultrathin layered double hydroxide nanosheets. ACS Appl Mater Interfaces 11(22): 20249-20256 (2019)

[63] Wang W, Xie G X, Luo J B. Superlubricity of black phosphorus as lubricant additive. ACS Appl Mater Interfaces 10(49): 43203-43210 (2018)

[64] Li J J, Cao W, Li J F, Ma M, Luo J B. Molecular origin of superlubricity between graphene and a highly hydrophobic surface in water. J Phys Chem Lett 10(11): 2978-2984 (2019)

[65] Holmberg K, Andersson P, Erdemir A. Global energy consumption due to friction in passenger cars. Tribol Int 47: 221-234 (2012)

[66] Liu H L, Liu H J, Zhu C C, Parker R G. Effects of lubrication on gear performance: A review. Mech Mach Theory 145: 103701 (2020)

[67] Townsend D P, Zaretsky E V, Scibbe H W. Lubricant and additive effects on spur gear fatigue life. $J$ Tribol 108(3): 468-475 (1986)

[68] Krantz T L, Kahraman A. An experimental investigation of the influence of the lubricant viscosity and additives on gear wear. Tribol Trans 47(1): 138-148 (2004)

[69] Krantz T L. Correlation of gear surface fatigue lives to lambda 
ratio (Specific Film Thickness). GRC-E-DAA-TN9030 (2013)

[70] Sagraloff N, Dobler A, Tobie T, Stahl K, Ostrowski J. Development of an oil free water-based lubricant for gear applications. Lubricants 7(4): 33 (2019)

[71] Yilmaz M, Mirza M, Lohner T, Stahl K. Superlubricity in EHL contacts with water-containing gear fluids. Lubricants 7(5): 46 (2019)

[72] Information. http://www.ruino.cn/news/2-603.html, 2019.

[73] Mutyala K C, Doll G L, Wen J G, Sumant A V. Superlubricity in rolling/sliding contacts. Appl Phys Lett 115(10): 103103 (2019)

[74] Björling M, Shi Y J. DLC and glycerol: Superlubricity in rolling/sliding elastohydrodynamic lubrication. Tribol Lett 67(1): 23 (2019)

[75] Holmberg K, Andersson P, Nylund N O, Makela K, Erdemir A. Global energy consumption due to friction in trucks and buses. Tribol Int 78: 94-114 (2014)

[76] Tormos B, Martín J, Carreño R, Ramírez L. A general model to evaluate mechanical losses and auxiliary energy consumption in reciprocating internal combustion engines. Tribol Int 123: 161-179 (2018)

[77] Ciulli E. A review of internal combustion engine losses Part 1: Specific studies on the motion of pistons, valves and bearings. Proceedings of the Institution of Mechanical Engineers, Part D: Journal of Automobile Engineering 206(4): 223-236 (1992)

[78] Chong W W F, Ng J H, Rajoo S, Chong C T. Passenger transportation sector gasoline consumption due to friction in Southeast Asian countries. Energ Convers Manage 158: 346-358 (2018)

[79] Ali M K A, Peng F M, Younus H A, Abdelkareem M A A, Essa F A, Elagouz A, Hou X J. Fuel economy in gasoline engines using $\mathrm{Al}_{2} \mathrm{O}_{3} / \mathrm{TiO}_{2}$ nanomaterials as nanolubricant additives. Appl Energ 211: 461-478 (2018)

[80] Esquivel-Gaon M, Nguyen N H A, Sgroi M F, Pullini D, Gili F, Mangherini D, Pruna A I, Rosicka P, Sevcu A, Castagnola V. In vitro and environmental toxicity of reduced graphene oxide as an additive in automotive lubricants. Nanoscale 10(14): 6539-6548 (2018)

[81] Larsson E, Olander P, Jacobson S. Boric acid as fuel additiveFriction experiments and reflections around its effect on fuel saving. Tribol Int 128: 302-312 (2018)

[82] Johnson B, Wu H X, Desanker M, Pickens D, Chung Y W, Wang Q J. Direct formation of lubricious and wear-protective carbon films from phosphorus- and sulfur-free oil-soluble additives. Tribol Lett 66(1): 2 (2017)
[83] Gupta N, Tandon N, Pandey R K. An exploration of the performance behaviors of lubricated textured and conventional spur gearsets. Tribol Int 128: 376-385 (2018)

[84] Siddaiah A, Kasar A K, Manoj A, Menezes P L. Influence of environmental friendly multiphase lubricants on the friction and transfer layer formation during sliding against textured surfaces. J Clean Prod 209: 1245-1251 (2019)

[85] Umehara N, Kitamura T, Ito S, Tokoroyama T, Murashima M, Izumida M, Kawakami N. Effect of carbonaceous hard coatings overcoat on friction and wear properties for al alloy sliding bearing in oil lubrication. In Advances in Mechanism and Machine Science. Uhl T, Ed. Cham, Switzerland: Springer, 2019: 3795-3803.

[86] Tao H, Tsai M T, Chen H W, Huang J C, Duh J G. Improving high-temperature tribological characteristics on nanocomposite CrAlSiN coating by Mo doping. Surf Coat Technol 349: 752-756 (2018)

[87] Akbarzadeh A, Khonsari M M. Effect of untampered plasma coating and surface texturing on friction and running-in behavior of piston rings. Coatings 8(3): 110 (2018)

[88] Tao G Q, Wang L F, Wen Z F, Guan Q H, Jin X S. Measurement and assessment of out-of-round electric locomotive wheels. Proc Inst Mech Eng, Part F: J Rail Rapid Transit 232(1): 275-287 (2016)

[89] Information. https://www.qianzhan.com/analyst/detail/220/ 190222-d32e255e.html, 2019.

[90] Information. http://www.tradeinvest.cn/information/4566/detail, 2019.

[91] Puls H, Klocke F, Lung D. Experimental investigation on friction under metal cutting conditions. Wear 310(1-2): 63-71 (2014)

[92] Sharma A K, Tiwari A K, Dixit A R. Effects of Minimum Quantity Lubrication (MQL) in machining processes using conventional and nanofluid based cutting fluids: A comprehensive review. J Clean Prod 127: 1-18 (2016)

[93] Irani R A, Bauer R J, Warkentin A. A review of cutting fluid application in the grinding process. Int J Mach Tools Manuf 45(15): 1696-1705 (2005)

[94] Brinksmeier E, Heinzel C, Wittmann M. Friction, cooling and lubrication in grinding. CIRP Ann 48(2): 581-598 (1999)

[95] Debnath S, Reddy M M, Yi Q S. Environmental friendly cutting fluids and cooling techniques in machining: A review. Journal of Cleaner Production 83: 33-47 (2014)

[96] Debnath S, Reddy M M, Yi Q S. Environmental friendly cutting fluids and cooling techniques in machining: A review. Journal of Cleaner Production 83: 33-47(2014) 
[97] Sharma A K, Tiwari A K, Dixit A R. Progress of nanofluid application in machining: A review. Mater Manufact Processes 30(7): 813-828 (2015)

[98] Ge D L, Deng J X, Duan R, Liu Y Y, Li X M, Yue H Z. Effect of micro-textures on cutting fluid lubrication of cemented carbide tools. Int $J$ Adv Manufact Technol 103(9-12): 3887-3899 (2019)

[99] Arslan A, Masjuki H H, Kalam M A, Varman M, Mufti R A, Mosarof M H, Khuong L S, Quazi M M. Surface texture manufacturing techniques and tribological effect of surface texturing on cutting tool performance: A review. Crit Rev Solid State Mater Sci 41(6): 447-481 (2016)

[100] Campa R, Szocik K, Braddock M. Why space colonization will be fully automated. Technol Forecast Soc Change 143: 162-171 (2019)

[101] Li H Q, Duan L C, Liu X F, Cai G P. Deployment and control of flexible solar array system considering joint friction. Multibody Syst Dyn 39(3): 249-265 (2017)

[102] Wu S N, Wang R, Radice G, Wu Z G. Robust attitude maneuver control of spacecraft with reaction wheel lowspeed friction compensation. Aerosp Sci Technol 43: 213-218 (2015)

[103] Hacker J M, Ying J Y, Lai P C. Reaction wheel friction telemetry data processing methodology and on-orbit experience. J Astronaut Sci 62(3): 254-269 (2015)

[104] Lu S L, Qi X Z, Hu Y, Li B, Zhang J W. Deployment dynamics of large space antenna and supporting arms. IEEE Access 7: 69922-69935 (2019)

[105] Li W, Fan X Q, Li H, Zhu M H, Wang L P. Probing carbon-based composite coatings toward high vacuum lubrication application. Tribol Int 128: 386-396 (2018)

[106] Zhuang W H, Fan X Q, Li W, Li H, Zhang L, Peng J F, Cai Z B, Mo J L, Zhang G G, Zhu M H. Comparing space

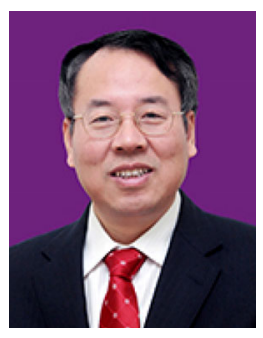

Jianbin LUO. He received his B.Eng. degree from Northeastern University in China in 1982, and got his M.Eng. degree from Xi'an University of Architecture and Technology in 1988. In 1994, he received his Ph.D. degree from Tsinghua University and then joined the faculty of Tsinghua University. Prof. Luo is an academician of the Chinese Academy of Sciences and a Yangtze River adaptability of diamond-like carbon and molybdenum disulfide films toward synergistic lubrication. Carbon 134: 163-173 (2018)

[107] Chen Q C, Wu G Z, Li D S, Li A, Shang L L, Lu Z B, Zhang G G, Wu Z G, Tian G K. Understanding the unusual friction behavior of TiN films in vacuum. Tribol Int 137: 379-386 (2019)

[108] Wang W Y, Wang Y L, Bao H F, Xiong B, Bao M H. Friction and wear properties in MEMS. Sens Actuators A-Phys 97-98: 486-491 (2002)

[109] Kim S H, Asay D B, Dugger M T. Nanotribology and MEMS. Nano Today 2(5): 22-29 (2007)

[110] Singh R A, Jayalakshmi S, Yoon E S, Pham D C, Ieee. Solutions for friction reduction at nano/microscale for MEMS actuators-based devices. In Proceedings of 2016 International Conference on Energy Efficient Technologies for Sustainability, Nagercoil, India, 2016: 874-876.

[111] Krim J. Controlling friction with external electric or magnetic fields: 25 examples. Front Mech Eng 5: 22 (2019)

[112] Leong J Y, Zhang J, Sinha S K, Holmes A, Spikes H, Reddyhoff T. Confining liquids on silicon surfaces to lubricate MEMS. Tribol Lett 59(1): 15 (2015)

[113] Renewables 2018 Global Status Report. 2018.

[114] Hussain A, Arif S M, Aslam M. Emerging renewable and sustainable energy technologies: State of the art. Renew Sust Energ Rev 71: 12-28 (2017)

[115] Evans M H. An updated review: White etching cracks (WECs) and axial cracks in wind turbine gearbox bearings. Mater Sci Technol 32(11): 1133-1169 (2016)

[116] Chen H, Tang T H, N. Aït-Ahmed, El Hachemi Benbouzid M, Machmoum M, El-Hadi Zaïm M. Attraction, challenge and current status of marine current energy. IEEE Access 6: $12665-12685$ (2018)

Scholar Distinguished Professor of Tsinghua University, Beijing, China. He was awarded the STLE International Award (2013), the CTI highest achievement award (2013), the Chinese National Technology Progress Prize (2008), the Chinese National Natural Science Prize $(2018,2001)$, and the Chinese National Invention Prize (1996). Prof. Luo has been engaged in the research of thin film lubrication and superlubricity. He has made keynote or plenary talks for 30 times on the international conferences. 


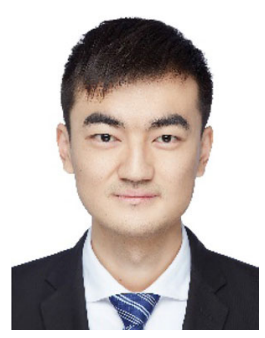

Xiang ZHOU. He obtained his bachelor degree in 2015 from Tsinghua University. After then, he became a Ph.D. candidate under the supervisor of Prof. Luo at the State Key Laboratory of Tribology, Tsinghua University. His research interests include trobological properties of 2D materials and phononic energy dissipation. 